Available online at www.sciencedirect.com

Science W Direct

\title{
Analysis of interactions in multicomponent polymeric systems: The key-role of inverse gas chromatography
}

\author{
J.M.R.C.A. Santos ${ }^{\mathrm{a}, *}$, J.T. Guthrie ${ }^{\mathrm{b}}$ \\ ${ }^{a}$ Department of Chemical Technology, School of Technology and Management, Polytechnic Institute of Bragança, \\ Campus de Santa Apolónia, 5301-857 Bragança, Portugal \\ ${ }^{\mathrm{b}}$ Department of Colour and Polymer Chemistry, The University of Leeds, Woodhouse Lane, Leeds, \\ West Yorkshire LS2 9JT, UK
}

Received 1 June 2005; received in revised form 18 July 2005; accepted 18 July 2005

Available online 8 September 2005

\begin{abstract}
The properties of a polymeric system are a consequence of the interactions that occur between the various components of these complex systems. These components may vary significantly in terms of chemical nature (e.g. organic/inorganic), physical properties (e.g. particle size, surface area, molecular weight), structural characteristics and proportion in the formulations composition. This review paper addresses the major approaches in use regarding the analysis of the interactions that occur between the polymeric system components and the use of such approaches in the interpretation of the chemical, physical and thermodynamic properties of these systems. Special attention is given to the technique of inverse gas chromatography.

A case study is presented, where use was made of inverse gas chromatography to characterize thermodynamically the surface of the major components of pigmented PC/PBT blends. The concept of Lewis acidity/basicity was used in the interpretation of the intermolecular interactions nature and potential in these blends, as encountered in phase separation and phase preferences phenomena and as expressed in the morphology, the physical and the mechanical properties of these commercially important composites.
\end{abstract}

(C) 2005 Elsevier B.V. All rights reserved.

Keywords: Interactions; Multicomponent polymeric systems; Inverse gas chromatography; Thermodynamic characterisation; Solubility parameter

\section{Introduction}

The strong correlations that exist between the morphology, the processing and the physical and the mechanical properties in multicomponent polymeric systems are well-recognised [1,2]. These aspects and correlations are a consequence of the interactions that occur between the various components of polymer-based systems. As the number of constituents in these systems increases, the ways in which the various components interact and become dispersed/segregated during processing and in service, become increasingly important. Among these added materials are the stabilisers, plasticizers, reinforcing fibres, pigments and other polymers.

In the particular case of polymer mixtures, the morphologies of two-component polymer blends have been widely discussed in the literature as these represent the more common commercial form of polymer blends. In response to commercial pressures and to the need for precisely tailored physical

\footnotetext{
* Corresponding author. Tel.: +351 933422158; fax: +351 213907481.

E-mail address: josesantos@gmx.co.uk (J.M.R.C.A. Santos).
} 
properties, more complex blends that consist of multiple components are under active development. In such blends, morphological concerns go beyond questions concerned with the dispersed phase size, anisotropy, etc., to include other issues, such as why one of the dispersed polymer phases may spontaneously encapsulate another [3] or encapsulate the filler particles [4]. Obviously, in multiphase polymer systems, interfaces and interphases must exit. Therefore, it is reasonable to assume that under equilibrium conditions, such effects must arise from interfacial energy differences among the blend components. Surface and interfacial phenomena have been proven to influence:

(i) the dispersion of minor phases in polymer matrices [5,6];

(ii) the processability of polymer blends and composites [7,8];

(iii) the mechanical properties of polymer blends $[9,10]$.

Moreover, it is well-known that, for polymer blends, the apparent properties and morphology often do not indicate an equilibrium situation [11]. For instance, in blends of an amorphous polymer and a semi-crystalline polymer, the phase behaviour is strongly dependent on blending and the cooling conditions. In the case of partial miscibility or of complete miscibility of the components in the molten state, the cooling rate and the kinetics of non-isothermal crystallisation influence the final extent of phase separation at room temperature. The attainment of the thermodynamic equilibrium is determined by the nature and magnitude of the interactions between the components of these systems, as reflected in the existence of intermolecular forces.

The use properties of polymer blends depend strongly on the miscibility (compatibility) of the polymers. Miscibility occurs when specific interaction forces develop between the two (at least) polymers $[12,13]$. Specific interactions may be in the form of hydrogen bonding, charge transfer complexes, acid-base type interactions, dipole moments and electron donor-acceptor complexes [14-18]. These specific interactions are of a highly directional nature and are present in addition to the dispersive forces. A current view, pioneered by Fowkes [14,19-25], which is increasingly accepted, suggests that the totality of specific interactions may be viewed as Lewis acid-base forces. This approach has been supported by experimental results [24].

Intermolecular forces that are operating between molecular segments of polymers and at particulate interfaces are frequently cited in the literature [3,26-35] as being responsible for the properties of the system as a whole. In the particular case of polymer nanocomposites, e.g. polymeric matrices filled with well-dispersed, high shape-factor nanofillers, the self-organisation of the polymer chains has been reported to be significantly influenced by the nature and magnitude of the intermolecular interactions between the inorganic and the polymeric components. For instance, in polyamide (e.g. Nylon-6) matrices filled with organoclays, important changes in the crystallisation behaviour of this polymer have been reported [36-39].

Control of Lewis acid-base (specific) interactions has gained increasing significance in industrial practice for optimising the performance of polymer composites [14,40,41]. This is because such intermolecular forces are known to dominate over dispersion intermolecular forces and dipole-dipole intermolecular forces [2,5,12-14,16,31,34,35,40-44]. This is clear in the definition of specific interactions, given by Huyskens et al. [16], "specific interactions are short-range, site-bounded cohesion forces that considerably weaken a given chemical bond of one of the partners". Furthermore, from a thermodynamic point of view, specific interactions between chemical moieties are required in order to obtain a negative excess free energy by mixing [45].

From the above description, it is clear that there is a link between component interactions on the one hand and the rheological, physico-chemical and mechanical properties of the system, on the other. 


\section{Thermodynamic requirements for miscibility in multicomponent polymeric systems}

The basic question when considering a multicomponent polymeric system concerns the extent of thermodynamic miscibility. Several polymer pairs are known to be miscible or partially miscible and many of these have become commercially important [2]. Considerable attention has been given to the origins of miscibility and to binary polymer-polymer phase diagrams. It is usually observed that high molar mass polymer pairs, showing partial miscibility, exhibit phase diagrams that indicate a lower critical solution temperature (LCST) [2,45-47]. In a polymer blend that exhibits LCST behaviour, the miscibility is higher at low temperatures. As temperature increases, phase separation occurs because the intermolecular attractive forces responsible for the miscible behaviour tend to disappear as the internal energy of the molecules becomes high enough to overcome them.

The classic Flory-Huggins theory and extensions of this model, have been very useful in providing an understanding of the phase behaviour of polymer blends [9]. Miscibility is understood to be the penetration of components on the molecular level, analogous to the behaviour of low molecular weight substances. Fundamentally, one thermodynamically describes the miscibility of two arbitrary components by the Gibbs free energy of mixing, $\Delta G_{\text {mix }}$ :

$$
\Delta G_{\text {mix }}=\Delta H_{\text {mix }}-T \Delta S_{\text {mix }}
$$

Here, $\Delta H_{\text {mix }}$ denotes the enthalpy of mixing and $\Delta S_{\text {mix }}$ denotes the entropy of mixing.

In Eq. (1), the combinatorial entropy of mixing of components 1 and 2 depends on the number of molecules present, according to Eq. (2) [2]:

$$
\frac{\Delta S_{\text {mix }}}{R T}=n_{1} \ln \phi_{1}+n_{2} \ln \phi_{2}
$$

Here, $\phi_{1}$ is the molar fraction of component 1 in the mix and $\phi_{2}$ is the molar fraction of component 2 in the mix. $R$ is the gas constant and $T$ is the temperature. The parameters $n_{1}$ and $n_{2}$ are the number of moles of molecules of components 1 and 2, respectively. Therefore, as the molar mass increases, the number of molecules per unit mass becomes small and the combinatorial entropy of mixing becomes negligibly small [48].

Any two components are mutually miscible if the mixing free energy of the systems meets the following conditions:

$$
\begin{aligned}
& \Delta G_{\text {mix }}<0 \\
& \left(\frac{\partial^{2} \Delta G_{\text {mix }}}{\partial \phi^{2}}\right)_{\mathrm{p}, \mathrm{T}}>0
\end{aligned}
$$

Here, $\phi$ is the molar fraction of a component.

For spontaneous mixing, the value of $\Delta G_{\text {mix }}$ must be negative. Thus, and bearing in mind the small contribution of the entropy of mixing to the free energy of mixing, exothermic mixtures $\left(\Delta H_{\text {mix }}<0\right)$ will mix spontaneously. On the other hand, for endothermic mixtures, miscibility will only occur at high temperatures. The condition expressed in Scheme 2 means that, mathematically, $\Delta G_{\text {mix }}(\phi)$ is a convex function of the composition of the mixture $(\phi)$. This results in the well-known phase diagram with its lower critical solution temperature or the upper critical solution temperature (UCST) either bimodal or spinodal. From the above, it follows that the mixing process, in blends exhibiting LCST behaviour, is an exothermic process and that the mixing process of blends exhibiting UCST behaviour is an endothermic process. However, most polymers are not fully miscible, so that a 
complete thermodynamic description is not possible since the phase separation diagram cannot be determined. This apparent "chemical incompatibility" results, in many cases, in the creation of a stable, finely dispersed distribution of the polymers in one another [9].

It should be mentioned that in order to explain phase separation that occurs on heating, i.e. LCST behaviour, the effect of volume changes on mixing must be considered [2]. This effect is described by equation-of-state theories, such as that developed by Flory and co-workers. The free volume contributions to the free energy are unfavourable and increase with temperature.

A question arises as to why miscible polymer pairs exist. In the case of polymers that are very similar physically and chemically, the occurrence of miscibility is comprehendible. If that is not the case, the major driving force for miscibility must be the enthalpic contributions to the free energy [2]. There are two ways, not mutually exclusive, of explaining favourable enthalpic contributions $[2,49]$ :

(a) positive interactions between the two polymers;

(b) unfavourable interactions between groups on the same polymer, causing an overall favourable interaction with another polymer.

Examples of favourable interactions between the polymer chains include specific intermolecular interactions, such as Lewis acid-base interactions involving hydrogen bonds. In these cases, phase separation that occurs on heating may be due to dissociation of the hydrogen bond matrix [2].

If the groups within the same polymer chain have a large enough unfavourable interaction, they will prefer to mix with another polymer group, in order to minimise the number of unfavourableunfavourable contacts $[49,50]$. A copolymer is often found to be miscible with another polymer over some range of monomer composition. The use of a cross term in the free energy expression allows for the description of this phenomenon [2]. It should, however, be pointed out that in the above case, if one simply ascribes a single solubility parameter to each monomer, it is impossible to predict an overall negative enthalpy of mixing [2]. Furthermore, it has been noted that a window of miscibility can be explained by the presence of a favourable specific interaction without recourse to a cross term. If one separates the normal dispersive forces from the specific interaction then, as a first approximation, when the solubility parameters of the two polymers are similar, the unfavourable dispersive interactions are small and the specific interactions yield miscibility.

Summarising, it can be said that for most miscible blends, the miscibility stems from specific interactions. However, the miscibility can also originate from reduction of unfavourable specific interactions between groups of the same polymer $[2,49,50]$.

\section{The solubility parameter}

One widely used approach to the quantification of interactions that occur in multicomponent polymeric systems is through the determination of "solubility" or "cohesion" parameters, $\delta_{\mathrm{T}}$. This parameter is, in effect, the square root of a cohesive energy density, as defined by Hildebrand in Eq. (3) [51-53]:

$$
\delta_{\mathrm{T}}=\left(\frac{\Delta H_{\mathrm{v}}}{V}\right)^{1 / 2}
$$

Here, $\Delta H_{\mathrm{v}}$ is the molar vaporisation energy of the substance and $V$ is its molar volume.

The solubility parameter was originally intended to be applied to substances whose cohesion arises from dispersion forces [34]. Moreover, this parameter seems to be of limited use with polymers 
that generally decompose before vaporisation enthalpies can be determined [11]. Nevertheless, the concept underlying the use of solubility parameters has been greatly expanded. The overall $\delta_{\mathrm{T}}$ can be divided into dispersion contributions and polar contributions. Often non-polar homomorphs of polar molecules can provide values for the dispersive contribution, $\delta_{\mathrm{d}}$ and the polar contributions, $\delta_{\mathrm{p}}$, can then be obtained from differences between $\delta_{\mathrm{T}}$ and $\delta_{\mathrm{d}}$. Further refinements due to Hansen, have introduced a three-component solubility parameter, which separates non-dispersive contributions into polar components and hydrogen bond components. This has been applied to organic liquids and some polymers [52]. Calculations of $\delta_{\mathrm{T}}$ for macromolecules can also be made from tabulated values of molar attraction constants, as carried out, for example, by Ryan et al. [54]. Extensive summaries of $\delta_{\mathrm{T}}$ and of other cohesion parameters are readily available in the literature [52,54]. Yet, some researchers [24], still consider that the use of solubility parameters is best restricted to the estimation of dispersion forces at interfaces and is less reliable as an indication of short-range polar, or acid-base interactions for semi-crystalline polymers and for cross-linked polymers.

For solids, polymers and many liquids, it is necessary to use indirect evaluation methods in the estimation of solubility parameters, as such materials have a vapour pressure that is too low to detect. Although these indirect methods are useful, they are also tedious and time consuming. Ultimately, the application of $\delta_{\mathrm{T}}$ to polymer systems is impeded by the following factors $[11,24,55]$ :

(1) No direct, experimental determinations of $\delta_{\mathrm{T}}$ for polymers exist to substantiate calculations and inferences (although relatively complex scattering techniques are being tested to this end).

(2) Available solubility parameters generally apply to polymers as solutes at very high dilution. The concentration dependence of $\delta_{\mathrm{T}}$ is difficult to assess.

(3) Data generally apply to room temperature conditions. The evaluation of a temperature dependence of behaviour is problematic.

\section{Interaction parameters from polymer solution theories}

Polymer solution thermodynamics, as developed firstly by Flory and Huggins (cited in refs. [56-60]), expresses the interaction between a polymer and a liquid in terms of a dimensionless parameter, $\chi_{1,2}$. This can be written as Eq. (4):

$$
\chi_{1,2}=\frac{\mu_{1}-\mu_{2}}{R T \varphi_{1}^{2}}-\left(\ln \varphi_{1}+\left(1-\frac{V_{1}}{V_{2}}\right) \varphi_{2}\right) \varphi_{2}
$$

The subscripts 1 and 2 denote the liquid (solvent) and the polymer (solute), respectively, $\mu$ the chemical potential, $\varphi$ the volume fractions and $V$ denotes molar volumes. Miscibility occurs when $\chi_{1,2}$ is lower than a critical value, or lower than zero.

The parameter $\chi_{1,2}$, as expressed in this manner, indicates intermolecular forces between the components of a polymer-liquid mixture and is not dependent on the choice of the intermolecular forces theoretical model. Its usefulness in practice is, nevertheless, limited because $\chi_{1,2}$ is usually determined by methods, such as vapour pressure lowering, osmotic pressure effects, equilibrium swelling of polymers by liquids, light scattering, etc. [24]. In all of these methods, the interaction parameter describes systems in which the polymer is at very high dilution. The temperature range over which the experimental data may be collected is narrow and often far from conditions of interest. Furthermore, interactions between the solid components of a polymer system are not possible to evaluate using this approach. 
The Flory-Huggins parameter, $\chi$, can be measured from the surface tensions that operate in a melt and by inverse gas chromatographic evaluations [14]. However, using the aforementioned techniques, it is not easy to measure $\chi$ exactly [9]. An alternative approach may be used to try to overcome that problem. This involves the calculation of the interfacial tensions from measurements of the thickness of the interfaces. This, in turn, is not easily achieved [2]. Nevertheless, using this method, an inverse proportionality of the interfacial tension to the thickness of the interlayer, as described by Raetzsch [9], is obtained. Other approaches exist to determine $\chi$ for polymer blends. These include the use of the glass transition temperature $\left(T_{\mathrm{g}}\right)$ [59] and the use of melting temperature $\left(T_{\mathrm{m}}\right)[13,46]$, based on the effect of miscibility on these characteristic temperatures.

\section{Work of adhesion and interfacial tension}

Researchers, such as Raetzsch et al. [9] and Liang et al. [24] studied miscibility phenomena of polymer blends based on the presence of interfaces in multiphase polymer mixtures, employing the thermodynamic work of adhesion between two different solids and interfacial tension determinations. This specific thermodynamic adhesion energy $\left(W_{\mathrm{a}}\right)$ or, in the case of a known adhesion distance, the specific adhesion strength between two solids, can be determined from the respective surface tensions, $\gamma_{1}$ and $\gamma_{2}$ and the interfacial tension $\gamma_{12}$ (Eq. (5)) (Dupré's equation):

$$
W_{\mathrm{a}}=\gamma_{1}+\gamma_{2}-\gamma_{12}
$$

The surface tension is a manifestation of intermolecular forces. The molecules at the surface of a liquid or a solid are influenced by unbalanced molecular forces, and therefore, possess additional energy in excess of the bulk molecules of the solid or liquid phase, that is, surface free energy.

Interactions in liquids and at polymer and solid surfaces and interfaces arise essentially from two types of intermolecular forces. The first are the comparatively weak van der Waals dispersion forces (London forces, Debye forces and Keesom forces), which are universal. The second type, the specific (non-dispersive) forces, often designated "polar" forces, are present solely in polar molecules.

The surface tension, $\gamma$, is the sum of the components $\gamma_{\mathrm{d}}$ and $\gamma_{\mathrm{p}}$, the apolar dispersive component and the "polar" component, respectively. Thus,

$$
\gamma=\gamma_{\mathrm{d}}+\gamma_{\mathrm{p}}
$$

The polar component includes the contribution of the dipole forces (electrostatic in origin) and of the acid-base (electron donor-electron acceptor) forces.

The interfacial tension, $\gamma_{12}$, between the polymers can be calculated from the individual surface tensions and their component terms [9] (Eq. (7)):

$$
\gamma_{12}=\gamma_{1}+\gamma_{2}-\frac{4 \gamma_{1}^{\mathrm{d}} \gamma^{\mathrm{d}}}{\gamma_{1}^{\mathrm{d}}+\gamma_{2}^{\mathrm{d}}}-\frac{4 \gamma_{1}^{\mathrm{p}} \gamma_{2}^{\mathrm{p}}}{\gamma_{1}^{\mathrm{p}}+\gamma_{2}^{\mathrm{p}}}
$$

Fowkes has proposed that non-dispersive interactions should be represented quantitatively as Lewis acid-base, or electron acceptor-donor effects [19-23]. Accordingly, the strength of an 
interface, as represented by the work of adhesion, can be written as:

$$
W_{\mathrm{a}}=W_{\mathrm{d}}+W_{\mathrm{ab}}
$$

Here, "ab" represents acid-base effects. $W_{\mathrm{ab}}$ can be estimated using the notion of acidic, $\gamma^{+}$and basic, $\gamma^{-}$, components of the surface tension, according to the van Oss equation [60]:

$$
W_{\mathrm{ab}}=2\left(\gamma_{1}^{+} \gamma_{2}^{-}\right)^{0.5}+2\left(\gamma_{1}^{-} \gamma_{2}^{+}\right)^{0.5}
$$

The contribution of the dispersive forces to the work of adhesion can be quantified by means of the Fowkes approach $[34,61]$ :

$$
W_{\mathrm{d}}=2\left(\gamma_{1}^{\mathrm{d}} \gamma_{2}^{\mathrm{d}}\right)^{0.5}
$$

Analogously to Eq. (8), the surface energy can be represented as:

$$
\gamma=\gamma_{\mathrm{d}}+\gamma_{\mathrm{ab}}
$$

The assumption is made that other non-dispersion (e.g. dipole) forces may be neglected. The total contribution of acid-base interaction to the surface tension is:

$$
\gamma_{\mathrm{ab}}=2\left(\gamma^{+} \gamma^{-}\right)^{0.5}
$$

It has been increasingly recognised that the convention adopted in first place by Fowkes for the non-disperive component of the free energy, $\gamma_{\mathrm{ab}}$, is more adequate to the description of these forces than is the "old" concept of polar interactions, $\gamma_{p}$. This is due to the greater contribution of the acidbase forces, in comparison with the contribution of the dipole forces, to the total "polar" forces, in liquids and at interfaces [28].

The approach described in the previous paragraphs has several drawbacks.

Eq. (6) is only valid provided that no reaction takes place between the polymers and is limited to polymers whose polar components and apolar components of the surface tension have been experimentally determined or theoretically estimated. Furthermore, knowledge of the surface tension components at wide temperature ranges is quite limited as far as published data are concerned. This is understood bearing in mind, for example, the commonly used contact angle method for the determination of surface tension values.

The quantitative measurement of the interfacial tension still remains a subject of controversy [24]. Some of the approaches used include the acid-base rationalisation of surface and interfacial energies, pioneered by Fowkes [19-22] and other, such as alternative acid-base rationalisation due to Good and co-workers, equation-of-state arguments by Neumann and co-workers and the association of surface and interfacial energies with the Gibbs-Thomson equation. Nevertheless, values of interfacial tension calculated by these various approaches can differ by more than two orders of magnitude [24].

Experimental methods for the determination of interfacial and surface tension include the abovementioned contact angle method, whose use must take into account the possible time dependence of contact angle values, the relatively narrow temperature range limitation and the influence of factors, such as the surface roughness and heterogeneity and bulk penetration of the liquid. Other experimental methods for the determination of the surface free energy include extrapolation of the surface tension of polymer melts to room temperature [55] and also the pendant drop and the spinning drop methods [24]. However, the latter two methods are complex equilibrium techniques and generally require long experimental times, putting in jeopardy the thermal stability of polymers [24]. 


\section{Inverse gas chromatography and quantification of interactions in multicomponent polymeric systems}

\subsection{Introduction to inverse gas chromatography (IGC)}

The growing awareness of the importance of solid surfaces, interfaces and interphases in determining the useful properties of polymeric systems, has led to the development of inverse gas chromatography as a useful technique in evaluating the potential for interaction of different components of polymer blends, composites and multicomponent polymeric systems. Data obtained from IGC experiments may, in favourable cases, correlate directly with observed performance criteria, such as colour development, gloss, rheological properties, adhesion and mechanical properties $[27,40,41]$.

The first papers on IGC go back 33 years. One paper was published in 1972 [62], five papers were published in 1973 [63-67] and from then the number of publications has increased significantly. In 1993, 93 papers were published, and since then, an increasingly number of papers has been published.

The fields of application of IGC include polymers, paper and other cellulosics, fillers and pigments, flavourings and perfumes, minerals and inorganic materials, food products and ingredients, packaging and coatings, pharmaceuticals and medical products, building materials, cosmetics, natural and artificial fibres, supported catalysts and microporous materials.

The main difference between conventional gas chromatography (GC) and IGC lies in the fact that the species of primary interest are not the volatile components injected but the material acting as the stationary phase, typically a powder, fibre or film. This material may be packed directly into the column, coated onto a suitable support or coated onto the walls of the column. This allows the investigation of the interactive nature via the degree of interaction with well-characterised volatile liquids/vapours ("probes"). Quantification of this interaction may be achieved by the determination of the retention time, $t_{\mathrm{r}}$, for a given probe.

In most uses, the quantity of probe vapour injected into the carrier gas is extremely small. Thus, the retention data relate to the thermodynamic interaction that occurs between polymer and the vapour when the polymer is highly concentrated, as in most practical situations. Furthermore, IGC experiments may be carried out over appreciable temperature ranges, so that the temperature dependence of thermodynamic interactions is no longer indeterminate.

The IGC technique has been extended to allow for measurements of interactions that occur between mixed stationary phase components [56,68]. Useful values of the Flory-Huggins parameter, $\chi$, may be obtained for polymer blends and for mixtures of polymers with fibres, pigment, etc.

Further advantages of IGC over other methods include:

(1) the ability to quantify strong interactions that occur between the support and the probe (strong interactions cannot be characterised by contact angle measurement because such interactions give rise to contact angles that are close to zero);

(2) nanorugosity and surface heterogeneity is not a problem as it is in the case of contact angle measurements;

(3) the fact that this approach is less time consuming than other methods;

(4) the fact that the method is accurate, versatile, with relatively easy sample preparation;

(5) The reality that there is no need for expensive equipment.

As well as providing thermodynamic information, the IGC technique is an excellent technique for determining phase transitions, for measuring adsorption properties and so on. This is illustrated by the 
following list, in which are compiled parameters/phenomena that can be studied by the IGC technique, together with relevant information sources:

(a) Flory-Huggins solubility parameters [13,14,64,69-72];

(b) crystallinity of semi-crystalline polymers $[63,70,73,74]$;

(c) phase separation phenomena in immiscible polymer blends [69,75-78];

(d) surface/bulk composition differences in polymeric systems [64,70,73,79];

(e) surface roughness (nanorugosity) of solids [66,80];

(f) surface areas of phase domains and molecular areas [73,74,81];

(g) surface energy of solids (dispersive and specific components of the surface free energy, enthalpy and entropy of adsorption) [67,75,82-85];

(h) infinite dilution activity coefficients [86];

(i) glass transition temperature, $T_{\mathrm{g}}$ and melting temperature, $T_{\mathrm{m}}$, of polymers [74];

(j) barrier properties of polymeric systems [73].

Given this range of parameters/phenomena and the continued growth of material science, it is reasonable to conclude that IGC studies will continue to play an important role in furthering an understanding of the behaviour of polymeric materials and in helping to design multicomponent systems that meet desired targets of performance and durability.

\subsection{Quantification of interactions in multicomponent polymeric systems}

The relationship between intermolecular interactions and system properties is particularly important in polymer compositions, bearing in mind the variety of polymers and additives that are used to achieve desired performance requirements. Some illustrative examples of the importance of the Lewis acid-base interactions, quantified by means of IGC, are described in the next paragraphs.

A strong correlation has been found by Liang et al. [24] between the interfacial tension of polymer pairs and their acid-base pair interaction, as determined by IGC. The relationship is inverse, with interfacial tensions decreasing as acid-base interactions increase. The existence of Lewis acidbase interactions among the components of a polymeric system may also be cited as a source of compositional variation at the surface, or within the bulk, of the system [64]. Raetzsch et al. [9] demonstrated that a correlation exists between the difference of the polar component of the interfacial tension and the particle size of the dispersed phase and the mechanical properties, in polymer blends.

The interaction of a filler with itself and with the fluid medium, influences to a large extent its state of dispersion, and in the end, the quality and the performance of the composition into which the filler is incorporated. If the acceptor and donor numbers of a filler are known, one can anticipate the behaviour of the filler with respect to the adsorption of polymers $[87,88]$ and to the mechanical properties of composites [41,89,90] and of film-forming polymers [91]. Good examples can be found in the literature concerning the way in which IGC characterisation, associated with controlled surface modification, leads to a better knowledge of the surface physico-chemistry of fillers $[87,90]$.

Schreiber et al. used IGC for the evaluation of Lewis acid-base interaction parameters for polyethylene, poly(vinyl chloride) and calcium carbonate [92]. The surface Lewis acid-base characteristics of the filler were controlled by microwave plasma surface treatments using acidic and basic vapours. It was concluded that the dispersion behaviour of the filler in the polymer matrixes and the mechanical properties at large deformation, are influenced by the acid-base interaction balance in the polymer-filler pair, as determined by IGC. 
The dispersion of surface-treated fillers in polymer matrixes has been studied by Boluk and Schreiber [6] by means of assessing the acid-base interaction potential of the major components of these systems by IGC. In the case of pigmented, plasticised poly(vinyl chloride), significant differences in rheological and mechanical properties have been observed [11] when the interaction balance within the system was altered by substituting a basic rutile titanium dioxide for one with acidic surface tendencies. Lewis acid-base surface properties of titanium dioxide particulates with surfaces modified with silica and/or alumina and the surface modification influence on the dispersion of the filler in a polymeric medium, have been studied using IGC by Lee et al. [93].

Ziani et al. [94] studied the dispersion stability of pigments in paint formulations and concluded that a correlation exists between the ease of dispersion and acid-base interaction parameters, as determined by IGC.

\subsection{The use of IGC for the determination of Flory-Huggins interaction parameters and solubility parameters}

The relationship between the basic information of IGC, the net retention volume, $V_{n}$ and the Flory-Huggins interaction parameter, $\chi$, may be written as expressed in Eq. $(13)[53,63,95,96]$ :

$$
\chi=\ln \left(\frac{R T v_{2}}{V_{n} p_{1}^{0} V_{1}}\right)-\left(1-\frac{V_{1}}{V_{2}}\right) \varphi_{2}-\frac{p_{1}\left(B_{11}-V_{1}\right)}{R T}
$$

Here, $v_{2}, V_{2}$ and $\varphi_{2}$ are the specific volume, the molar volume and the volume fraction of the polymer. $V_{1}$ and $p_{1}^{0}$ refer to the molar volume and the saturation vapour pressure of the molecular probe. $B_{11}$ is the second virial coefficient of the probe and corrects for non-ideality in the vapour phase. $R$ is the ideal gas constant and $T(\mathrm{~K})$ is the column temperature.

When $\chi$ values are determined for a given polymer or other non-volatile component of a polymer system and a series of vapours for which solubility parameter values are known, the IGC method provides a unique way to determine $\delta_{\mathrm{T}}$ for the polymer phase. The method is based on the principle that the Flory-Huggins interaction parameter, $\chi$, can be related to $\delta_{\mathrm{T}}$ by combining Hildebrand-Scatchard solution theory with Flory-Huggins theory [53]:

$$
\chi=\frac{V_{1}}{R T}\left(\delta_{1}-\delta_{2}\right)^{2}
$$

Here, $V_{1}$ is the molar volume of the probe and $\delta_{1}$ and $\delta_{2}$ are the solubility parameters of the probe and stationary phase, respectively.

The necessary relationship, between $\chi$ and solubility parameters, states that $[53,97,98]$ :

$$
\frac{\delta_{1}^{2}}{R T}-\frac{\chi}{V_{1}}=\left(\frac{2 \delta_{2}}{R T}\right) \delta_{1}-\left(\frac{\delta_{2}^{2}}{R T}+\frac{\chi_{\mathrm{s}}}{V_{1}}\right)
$$

Here, $\delta_{1}$ is the solubility parameter of component 1 and $\delta_{2}$ is the solubility parameter of component $2, V_{1}$ the molar volume of the probe and $\chi_{\mathrm{s}}$ is the entropic contribution to $\chi$. A plot of the left hand side of Eq. (15) versus $\delta_{1}$ should lead to a straight line, with $\delta_{2}$ obtained from its slope.

The great advantage here is the ability to evaluate $\delta_{2}$ for essentially pure polymers at temperatures that are relevant to identified applications. The generality and usefulness of the method has been demonstrated frequently in the work of Price [99].

Thermodynamic interactions between mixed stationary phases may be obtained from IGC as first proposed by Su et al. [56] and followed by other research laboratories [68,77,96]. The approach calls 
for the experimental determination of $\chi_{1,2}$ and $\chi_{1,3}$, using common vapour probes, to characterise any desired pure components 2 and 3 . These solids may then be mixed to any suitable composition, a column prepared for IGC and an overall interaction parameter, $\chi_{1(2,3)}$ evaluated. The term $\chi_{1(2,3)}$ is related to compositional variables through use of an extension of Scott's ternary solution theory. The results are most frequently written as [77,96]:

$$
\chi_{1(2,3)}=\left(\chi_{1,2}\right) \varphi_{2}+\left(\chi_{1,3}\right) \varphi_{3}+\left(\chi_{2,3}^{\prime}\right) \varphi_{2} \varphi_{3}
$$

Here, $\chi_{2,3}^{\prime}=\left(\chi_{2,3}\right) V_{1} / V_{2}$. The parameter for the interaction of mixed polymeric and/or nonpolymeric solids is thereby normalised to the size of the vapour phase molecule.

The attractiveness of this flexible and relatively easy experimental route to valuable information concerning the miscibility of system components is evident. Difficulties arise however, in that $\chi_{2,3}^{\prime}$ can vary with the selection of the vapour probe. This problem has been the subject of much discussion $[64,70,71,100-102]$. Shi and Shreiber [70] state that the probe dependence of $\chi_{2,3}$ is due to two major contributing factors. Firstly, the surface composition of a mixed stationary phase will rarely, if ever, correspond to the composition of the bulk. Thermodynamic requirements to minimise the surface free energy of the stationary phase will favour the preferential concentration, at the surface, of the component with the lower (lowest) surface free energy $[40,64,70,79]$. Thus, the values of $\varphi_{2}$ and $\varphi_{3}$, as defined by the bulk composition of mixtures, are inapplicable to Eq. (16). Instead, a graphical method was proposed by Shi and Schreiber [70] to evaluate the effective volume fraction and to correct the problem. Secondly, since $\chi_{1,2}$ and $\chi_{1,3}$ will not usually be equal, it follows that the volatile phase will partition preferentially to the component that has the lower pertinent $\chi_{1, x}$ value. Thus, the partitioning must vary with each probe, inevitably affecting the $\chi_{2,3}^{\prime}$ datum.

\subsection{IGC and the quantification of Lewis acidity/basicity parameters}

Due to the dynamic nature of IGC experiments, the retention time is dependent on the flow rate of the carrier gas. Therefore, the retention time is usually converted into a net retention volume, $V_{n}$, which may be defined as the volume of carrier gas that is required to elute a given probe as follows:

$$
V_{n}=\left(t_{\mathrm{r}}-t_{\mathrm{o}}\right) F C J
$$

Here, $t_{\mathrm{o}}$ is the retention time of a non-interacting probe species, either air, or more commonly, methane, $F$ the carrier gas flow rate in $\mathrm{cm}^{3} / \mathrm{s}$ and $J$ is the term correcting for the compressibility of the carrier gas, such that:

$$
J=1.5 \frac{\left(\frac{P_{\mathrm{i}}}{P_{\mathrm{o}}}\right)^{2}-1}{\left(\frac{P_{\mathrm{i}}}{P_{\mathrm{o}}}\right)^{3}-1}
$$

Here, $P_{\mathrm{i}}$ and $P_{\mathrm{o}}$ are the inlet and outlet pressures of the carrier gas, respectively. $C$ is a correction factor, allowing for the vapour pressure of the water at the temperature of the bubble flow meter used to determine the flow rate. Thus,

$$
C=1-\frac{P_{\mathrm{H}_{2} \mathrm{O}}}{P_{\mathrm{O}}}
$$

Here, $P_{\mathrm{H}_{2} \mathrm{O}}$ is the vapour pressure of the water in the flow meter, at the temperature of measurement. 
The retention time, as defined by Eq. (17), is known as the net retention volume. This may be normalised per gram of interacting material present in the stationary phase, yielding the specific retention volume:

$$
V_{\mathrm{g}}=\frac{V_{n}}{m}
$$

Here, $m$ is the mass of interacting stationary phase.

\subsubsection{Thermodynamic considerations}

The net retention volume, $V_{n}$, is a measure of the time that the probe is adsorbed on the stationary phase and a measure of the time that the molecule is present in the carrier gas, under isothermal conditions. Therefore, the net retention volume is expressed by a partition function. Strictly, the net retention volume can be divided into two components: a term that is related to bulk absorption (and therefore, to the volume of adsorbate) and a term that is related to the surface adsorption (and thus, to the adsorbate surface area) $[103,104]$. The relationship can be expressed as:

$$
V_{n}=k_{\mathrm{a}} V+k_{\mathrm{s}} A
$$

Here, $k_{\mathrm{s}}$ and $k_{\mathrm{a}}$ are the partition coefficients, for the surface adsorption and the bulk absorption, respectively. $V$ and $A$ are the volume and surface area of the adsorbate, respectively. Eq. (21) is used in gas-liquid chromatography. As far as pigments and glassy polymers are concerned, the bulk absorption can be, generally, disregarded. Thus, under such conditions, Eq. (21) simplifies to [104,105]:

$$
V_{n}=k_{\mathrm{S}} A
$$

where $k_{\mathrm{s}}$ can be formally defined as a partition function that accounts for the probe excess concentration on the surface, $\Gamma$ and its concentration on the gas phase, $c$. Thus,

$$
k_{\mathrm{s}}=\frac{\mathrm{d} \Gamma}{\mathrm{d} c}
$$

Under infinite dilution conditions, Henry's Law is obeyed. Thus,

$$
\left(\frac{\mathrm{d} \Gamma}{\mathrm{d} c}\right)_{\Gamma \rightarrow 0}=\frac{\Gamma}{c}
$$

For these conditions, the partition coefficient, expressed by Eq. (23), is independent of the probe concentration in the gas phase. Experimentally, this fact can be verified by obtaining constant retention times, injecting a probe amount that is lower than a certain limit. The probe concentration, under such conditions, can be expressed by:

$$
c=\frac{p}{R T}
$$

Here, $p$ is the partial pressure of the probe and $R$ is the universal gas constant. From Eqs. (23)(25), one gets [105]:

$$
k_{\mathrm{s}}=\Gamma \frac{R T}{p}
$$


where $\Gamma$ is related to the pressure on the surface through the Gibbs equation [105]:

$$
\Gamma=\frac{1}{R T} p\left(\frac{\mathrm{d} \pi}{\mathrm{d} p}\right)
$$

Here, $\pi$ is the pressure of the probe on the surface and can be defined as the reduction in the surface free energy of the probe due to vapour adsorption. In the region, where Henry's Law is valid, the reduction in the surface free energy of the stationary phase due to the probe, is a linear function of the probe's partial pressure. Thus,

$$
\frac{\mathrm{d} \pi}{\mathrm{d} p} \rightarrow \frac{\pi}{p}
$$

Combining Eqs. (26)-(28), one gets [105]:

$$
k_{\mathrm{s}}=\frac{\Gamma R T}{p}=\frac{\pi}{p}=\frac{V_{n}}{A}
$$

The free energy of adsorption can be compared with the change in the surface free energy that is due to the adsorption of one mole of probe molecules, from a reference gas phase, to a reference adsorption phase, as expressed in Eq. (30) [105]:

$$
\Delta G_{\mathrm{a}}=-R T \ln \left(\frac{P_{\mathrm{s}}^{\mathrm{s}}}{P_{\mathrm{g}}^{\mathrm{s}}}\right)
$$

Here, $\Delta G_{\mathrm{a}}$ is the difference in the free energy that is related to the isothermal adsorption of one mole of probe molecules in the reference gas phase, at a pressure $P_{\mathrm{g}}^{\mathrm{s}}$, in a reference adsorption phase, at a pressure $P_{\mathrm{s}}^{\mathrm{s}}$. The reference vapour pressure of the probe, in the gas phase, must be expressed such that its value corresponds to a surface pressure in the Henry's Law region. This can be attained by manipulating the relevant portion of Eq. (29), i.e. $p=\pi / k s$. Thus [105],

$$
\Delta G_{\mathrm{a}}=-R T \ln \left(\frac{V_{n} P_{\mathrm{s}}^{\mathrm{s}}}{\pi A}\right)
$$

Here, $A$ is the adsorbate' surface area, $P_{\mathrm{s}}^{\mathrm{s}}$ and $\pi$ are the reference gas pressure and the reference surface pressure, respectively. DeBoer defined the surface pressure as the pressure at which the distance between two-probe molecules is equal to the distance in the standard gas phase. Thus, $\pi=3.38 \times 10^{-4} \mathrm{Nm}^{-1}$ and $P_{\mathrm{g}}^{\mathrm{s}}=101.3 \mathrm{kPa}$ [104-106]. The surface area is constant between experiments, and therefore, Eq. (31) can be reduced to [105]:

$$
\Delta G_{\mathrm{a}}=-R T \ln \left(V_{n}\right)+K
$$

Here, $K$ is a term that includes all the constants that are present in Eq. (31).

\subsubsection{Dispersive component of the surface free energy of solid surfaces}

Three approaches are commonly employed in the analysis of the dispersive component of the surface free energy of solid surfaces via IGC. These are due to Fowkes [25,41,61,80,107-114] (referred to as Schultz and Lavielle approach, by some authors), Dorris and Gray [115] and Flour and Papirer [116]. 
The approach of Fowkes is based on his definition of work of adhesion between two apolar species [34]. Thus [24],

$$
W_{\mathrm{a}}=2\left(\gamma_{\mathrm{s}}^{\mathrm{d}} \gamma_{1}^{\mathrm{d}}\right)^{0.5}
$$

Here, $\gamma_{\mathrm{s}}^{\mathrm{d}}$ and $\gamma_{1}^{\mathrm{d}}$ are the dispersive component of the surface tension of a solid and of a liquid, respectively. According to Fowkes, the free energy of adsorption can be defined as:

$$
-\Delta G_{\mathrm{a}}=N_{\mathrm{A}} a W_{\mathrm{a}}+K^{\prime}
$$

Here, $N_{\mathrm{A}}$ is Avogadro's constant and " $a$ " is the molecular surface area of the adsorbed species. As defined by Eq. (34), the molar free energy of adsorption, $-\Delta G_{\mathrm{a}}$, is equal to the sum of the work of adhesion for the surface area occupied by one mole of molecules. Thus, it is equal and opposite to the work required to separate the area of interface created by one mole of molecules. The molar free energy of adsorption can be related to the retention volume using Eq. (32). From Eqs. (32)-(34), one obtains:

$$
R T \ln \left(V_{n}\right)=2 N_{\mathrm{A}} a\left(\gamma_{\mathrm{s}}^{\mathrm{d}}\right)^{0.5}\left(\gamma_{1}^{\mathrm{d}}\right)^{0.5}+K^{\prime \prime}
$$

From the above equation, a plot of $R T \ln \left(V_{n}\right)\left(\right.$ or $\left.R T \ln \left(V_{\mathrm{g}}\right)\right)$, as a function of $a\left(\gamma_{1}^{\mathrm{d}}\right)^{0.5}$ will yield a slope of $2 N_{\mathrm{A}} a\left(\gamma_{\mathrm{S}}^{\mathrm{d}}\right)^{0.5}$ and an intercept of $K^{\prime \prime}$. Values of $a\left(\gamma_{1}^{\mathrm{d}}\right)^{0.5}$ can be found in the literature [61,117]. Selected values are presented in Table 1, corresponding to probe molecule surface area values reported $[41,61,117]$ for the apolar probes most commonly used in IGC studies.

The method, however, does not always yield reliable values of $\gamma_{\mathrm{s}}^{\mathrm{d}}$. The reason for this is the uncertainty of the molecular surface area values of the adsorbed species [25,105,118]. Molecular areas of adsorbed molecules may be distorted by forces that are exerted by the surface. Non-spherical molecules, such as alkanes may lie "flat" or "head-to-tail" in the interface. Furthermore, different methods are in use for the estimation of the molecular areas, which may result, in some cases, in different values [111]. Also, the temperature influence on the molecular areas is not usually taken into account [25,118]. Consequently, IGC evaluations of $\gamma_{\mathrm{s}}^{\mathrm{d}}$, using this approach, must be viewed with some caution. Corrections for the values of the molecular area of adsorbed probes that take into account the aforementioned factors can be found in the references cited.

The approach of Dorris and Gray $[105,107,115,119,120]$ is similar to that of Fowkes. This approach involves the use of molecular surface areas to elucidate the dispersive surface free energies, derived via the dispersive component of the work of adhesion.

The method is based on calculation of the incremental free energy of adsorption of a $-\mathrm{CH}_{2}-$ group, for which the dispersive component of the surface tension is known to be $35.6 \mathrm{~mJ} / \mathrm{m}^{2}$ at $20{ }^{\circ} \mathrm{C}$ [105]. The free energy of adsorption of a $-\mathrm{CH}_{2}-$ group may be related to the dispersive component of

Table 1

\begin{tabular}{ll} 
Values of $a\left(\gamma_{1}^{\mathrm{d}}\right)^{0.5}$ for several $n$-alkanes & \\
\hline$n$-Alkane & $a\left(\gamma_{1}^{\mathrm{d}}\right)^{0.5}\left(\mathrm{~cm}^{2}\left(\mathrm{~mJ} \mathrm{~cm}^{-2}\right)^{0.5}\right)$ \\
\hline$n$-Hexane & $2.21 \mathrm{E}-16$ \\
$n$-Heptane & $2.57 \mathrm{E}-16$ \\
$n$-Octane & $2.91 \mathrm{E}-16$ \\
$n$-Nonane & $3.29 \mathrm{E}-16$ \\
$n$-Decane & $3.63 \mathrm{E}-16$ \\
$n$-Undecane & $3.99 \mathrm{E}-16$ \\
\hline
\end{tabular}


the surface tension via [105]:

$$
\gamma_{\mathrm{s}}^{\mathrm{d}}=\frac{\left(R T \ln \frac{V_{n}\left[\mathrm{C}_{n+1} \mathrm{H}_{2 n+4}\right]}{V_{n}\left[\mathrm{C}_{n} \mathrm{H}_{2 n+2}\right]}\right)^{2}}{4 N_{\mathrm{A}}^{2} a_{\mathrm{CH}_{2}}^{2} \gamma_{\mathrm{CH}_{2}}}
$$

Here $\left(V_{n}\left[\mathrm{C}_{n+1} \mathrm{H}_{2 n+4}\right]\right) /\left(V_{n}\left[\mathrm{C}_{n} \mathrm{H}_{2 n+2}\right]\right)$ corresponds to the difference in the free energy of adsorption arising from introducing an additional $-\mathrm{CH}_{2}$-into the carbon chain of a $n$-alkane probe. The other terms have the definition given earlier. Care should also be taken when using Eq. (36) because the value of the molecular area of a $-\mathrm{CH}_{2}-$ group, usually taken as $0.6 \mathrm{~nm}^{2}$, may not be the more accurate value, as has been recognised by Dorris and Gray themselves [115]. This drawback has been studied by Goss [107], who proposed corrections for the approach. Another frequently used approach for the determination of $\gamma_{\mathrm{s}}^{\mathrm{d}}$, is that of Schultz and Lavielle, which uses an equation that is equivalent to Eq. (36), resulting in identical numerical values [107].

The method of Papirer and Flour [104-106,116] employs a different treatment to the retention times data. In this case, the free energy of adsorption of each probe is plotted as a function of the logarithm of the probe vapour pressure at the column temperature (or chosen reference temperature). The data for $n$-alkanes define a straight line of negative slope that may be used as a reference to define the potential of the surface to undergo dispersive interactions. The slope of the reference line, in this case, is not related to the dispersive surface tension of the solid phase. The basis of the approach is empirical in nature.

Papirer et al. argue $[104,106]$ that the use of the vapour pressure of the probe in subsequent data manipulation is preferable, as it represents a readily determined macroscopic quantity and eliminates uncertainties that arise from the estimation of the molecular surface area of the probe and from the lack of data for $\gamma_{1}^{\mathrm{d}}$ at different temperatures. However, for surfaces with very high energy, such as graphite, this method has been shown to give unrealistic values [107]. This approach can, nevertheless, be used to determine the specific component of the energy of adsorption in an analogous procedure to that described below. Another approach, much less in use, is that of Sawyer and Brookman [105,107,121], which makes use of the boiling point, $T_{\mathrm{b}}$, of the probes instead of the logarithm of the saturated vapour pressure.

Other methods include the Dong approach [80,122-124] (based on the use of the molar deformation polarisation of the probe molecules), the Donnet approach [121-125] (based on the ionisation potential of the adsorbent and adsorbate and on the deformation polarizability), the Chehimi approach $[80,121,122]$ (based on the enthalpy of vaporisation of the probe molecules) and the Brendle and Papirer approach $[66,80,126]$.

The Brendle and Papirer approach is based on the use of a topological index that accounts for the geometry of the probe. This topological index replaces $a\left(\gamma_{1}^{\mathrm{d}}\right)^{0.5}$ in the determination of $\gamma_{1}^{\mathrm{d}}$ by Dorris and Gray approach. The other alternative approaches mentioned allow for the determination of quantities that are directly related to $\gamma_{1}^{\mathrm{d}}$, from a plot of $R T \ln \left(V_{n}\right)\left(\right.$ or $\left.R T \ln \left(V_{\mathrm{g}}\right)\right)$, as a function of the mentioned probe properties and/or related quantities.

Of the methods mentioned, the approach of Fowkes has proven to be the most useful, due to its graphical approach, and most importantly, due to its provision of the dispersive component of the surface tension.

\subsubsection{Quantification of the Lewis acid-base interaction capability of a material}

A Lewis acid is a molecule or ion whose incomplete electronic arrangement allows it to bind to another species by accepting an electron pair from that species. A Lewis base is a molecule or ion 
capable of donating an electron pair to a Lewis acid and resulting in the formation of coordination bonds [127].

If a Lewis acid-base interaction occurs, as is the case with polar probes, there will be a corresponding specific component contribution to the overall free energy of adsorption, in addition to the dispersive component. Thus,

$$
\Delta G_{\mathrm{a}}=\Delta G_{\mathrm{a}}^{\mathrm{d}}+\Delta G_{\mathrm{a}}^{\mathrm{s}}
$$

Here, $\Delta G_{\mathrm{a}}^{\mathrm{d}}$ is the term that represents the dispersive Lifshitz-van der Waals contribution to the total free energy of adsorption, $\Delta G_{\mathrm{a}} . \Delta G_{\mathrm{a}}^{\mathrm{s}}$ represents the contribution to the free energy of adsorption by any Lewis acid-base (specific) interactions. Commonly used polar probes include dichloromethane (DCM), trichloromethane (TCM), diethyl ether (DEE), acetone (Acet), tetrahydrofuran (THF) and ethyl acetate (EtAcet).

The determination of the non-dispersive, specific component of the free energy of adsorption is carried out graphically. The "Fowkes plot" (Fig. 1) typically yields a straight line for a homologous series of $n$-alkanes, enabling linear regression to establish a relationship between $a\left(\gamma_{1}^{\mathrm{d}}\right)^{0.5}$ and $R T \ln \left(V_{n}\right)$ (or $R T \ln \left(V_{\mathrm{g}}\right)$ ). Thus, any specific interactions result in a value of $-\Delta G_{\mathrm{a}}$ that is greater than the value that is attributable to purely dispersive interactions for a species with a particular value of $a\left(\gamma_{1}^{\mathrm{d}}\right)^{0.5}$.

If predominantly monopolar probes are used in the characterisation of the adsorbate, the interaction with a Lewis basic probe is a measure of the Lewis acidity of the surface. Conversely, a Lewis acidic species will undergo specific interactions with basic sites on the adsorbate.

From Eqs. (32) and (37), $-\Delta G_{\mathrm{a}}^{\mathrm{s}}$ may be defined as:

$$
-\Delta G_{\mathrm{a}}^{\mathrm{s}}=R T \ln \left(\frac{V_{n}}{V_{n, \text { ref }}^{\mathrm{d}}}\right)
$$

Here, $V_{n}$ is the retention volume of the polar probe and $V_{n, \text { ref }}^{\mathrm{d}}$ is the retention volume that is derived from the $n$-alkanes reference line. The procedure is illustrated in Fig. 1.

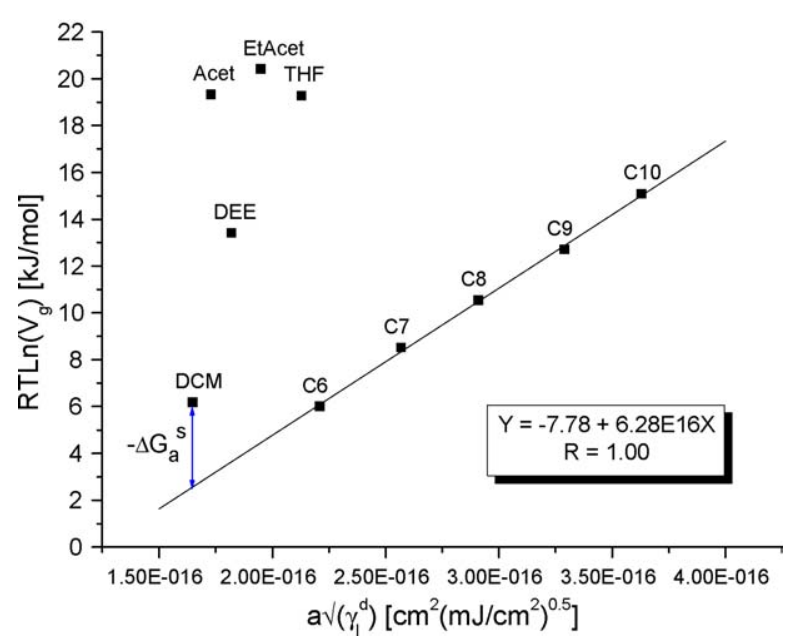

Fig. 1. Typical Fowkes plot. Energy of adsorption $\left(R T \ln \left(V_{\mathrm{g}}\right)\right)$ vs. $a \times \sqrt{\gamma_{\mathrm{d}}^{1}}$ of $n$-alkanes and polar probes on the surface of C.I. Pigment Blue 28, at $T=313$ K. 
Any of the aforementioned approaches used for the estimation of the dispersive component of the surface free energy, that differ in terms of the quantity $R T \ln \left(V_{n}\right)$ is plotted against, can be used to determine the value of $-\Delta G_{\mathrm{a}}^{\mathrm{s}}$, according to the method expressed in Eq. (38) and illustrated in Fig. 1.

The van't Hoff equation,

$$
\frac{\mathrm{d} \ln k_{\mathrm{s}}}{\mathrm{d}(1 / T)}=\frac{-\Delta H_{\mathrm{a}}}{R}
$$

shows that the change in the partition coefficient, $k_{\mathrm{s}}$ (and therefore, the free energy of adsorption) as a function of reciprocal temperature, must be constant to yield a single value of the enthalpy of adsorption, $\Delta H_{\mathrm{a}}$. Under the assumption of the temperature independence of the enthalpy component, the corresponding change in entropy is related to the change in the enthalpy of adsorption and the change in the free energy of adsorption, by:

$$
\Delta G_{\mathrm{a}}=\Delta H_{\mathrm{a}}-T \Delta S_{\mathrm{a}}
$$

Here, $\Delta G_{\mathrm{a}}, \Delta H_{\mathrm{a}}$ and $\Delta S_{\mathrm{a}}$ are the corresponding free energy, enthalpy and entropy changes upon adsorption of a probe species by the adsorbate. The values of $\Delta H_{\mathrm{a}}$ and $\Delta S_{\mathrm{a}}$, concerning a probe molecule, are determined plotting $\Delta G_{\mathrm{a}} / T$ as a function of $1 / T$. The value of $\Delta H_{\mathrm{a}}$ and of $\Delta S_{\mathrm{a}}$ are determined from the slope and from the intercept, respectively. If the specific component of the surface free energy, $\Delta G_{\mathrm{a}}^{\mathrm{s}}$, relating to a polar probe, is plotted against the reciprocal temperature, then the specific component of the enthalpy of adsorption, $\Delta H_{\mathrm{a}}^{\mathrm{s}}$ and the specific component of the entropy of adsorption, $\Delta S_{\mathrm{a}}^{\mathrm{s}}$, can be determined. Also, if the dispersive component of the surface free energy, $\Delta G_{\mathrm{a}}^{\mathrm{d}}$, relating to a apolar probe, or a polar probe, is plotted against the reciprocal temperature, then the dispersive component of the enthalpy of adsorption, $\Delta H_{\mathrm{a}}^{\mathrm{d}}$ and the dispersive component of the entropy of adsorption, $\Delta S_{\mathrm{a}}^{\mathrm{d}}$, can be determined.

Both the Lewis acidity and the Lewis basicity of a material contribute to the value of $\Delta H_{\mathrm{a}}^{\mathrm{s}}$ when that material is involved in intermolecular interactions. The approach of Gutmann [128] allows for the quantification of the Lewis acidity and of the Lewis basicity of a material, from $\Delta H_{\mathrm{a}}^{\mathrm{s}}$ values.

The value of the Lewis acidity constant, $K_{\mathrm{a}}$ and of the Lewis basicity constant, $K_{\mathrm{b}}$, is calculated using Eq. (41) [128]:

$$
-\Delta H_{\mathrm{a}}^{\mathrm{s}}=K_{\mathrm{a}} \times \mathrm{DN}+K_{\mathrm{b}} \times \mathrm{AN}
$$

Here, DN and AN are Gutmann's donor and acceptor numbers, respectively, corresponding to the polar probes [61,117,127]. Gutmann [127] defines DN as the molar enthalpy of mixing of a base with reference to the acceptor, $\mathrm{SbCl5}$. In contrast, $\mathrm{AN}$ is not an enthalpy parameter, but is defined as the relative ${ }^{31} \mathrm{P}$ NMR shift in triethylphosphine oxide, when this substance is reacted with an acceptor solvent. AN is scaled arbitrarily, ranging from zero when the solvent is hexane to 100 when the solvent is a dilute solution of the reference acceptor, $\mathrm{SbCl}_{5}$, in 1,2-dichloroethane.

A procedure has been suggested by Riddle and Fowkes [61] to resolve the inconsistency in the units of DN and AN. They have shown that the ${ }^{31} \mathrm{P}$ NMR shift of triethylphosphine oxide, $\mathrm{Et}_{3} \mathrm{PO}$, dissolved in acidic solvents (the criterion used in Gutmann's approach for the definition of AN), can be divided into dispersive contributions and true acid-base contributions. These authors also found that the dispersive contribution to the NMR shifts is directly proportional to calorimetric determinations of the enthalpies of dispersive interactions between $\mathrm{Et}_{3} \mathrm{PO}$ and acidic liquids. A new acceptor number $\mathrm{AN}^{*}$ is, therefore, obtained that has the same units as DN. Riddle and Fowkes suggest that $\mathrm{AN}^{*}$ be 
obtained from the simplified expression:

$$
\mathrm{AN}^{*}=0.288\left(\mathrm{AN}-\mathrm{AN}^{\mathrm{d}}\right)
$$

Here, $\mathrm{AN}^{\mathrm{d}}$ is the dispersive contribution reported by the authors [61]. Thus, Eq. (41) now becomes:

$$
-\Delta H_{\mathrm{a}}^{\mathrm{s}}=K_{\mathrm{a}} \times \mathrm{DN}+K_{\mathrm{b}} \times \mathrm{AN}^{*}
$$

Plotting $\frac{-\Delta H_{\mathrm{a}}^{\mathrm{s}}}{\mathrm{AN}_{*}^{*}}$ against $\frac{\mathrm{DN}}{\mathrm{AN}^{*}}$ gives $K_{\mathrm{a}}$ as the slope and $K_{\mathrm{b}}$ as the intercept. In Table 2 are summarised the values of $\mathrm{AN}^{*}$ and $\mathrm{DN}$, the values of the surface area and the values of $a\left(\gamma_{1}^{\mathrm{d}}\right)^{0.5}$ for the polar probes most commonly used in IGC studies [41,61,117,128-130].

A commonly used alternative approach for the quantification of the Lewis acid-base character of a surface is due to Drago and co-workers [26,34,131]. Here, acid-base pairs are equated to a set of four empirical parameters $\left(C_{\mathrm{a}}, E_{\mathrm{a}}\right.$ and $\left.C_{\mathrm{b}}, E_{\mathrm{b}}\right)$, based on enthalpies of mixing. The acidity and the basicity of a substance are given by parameters expressing covalent $(C)$ and electrostatic $(E)$ contributions. The Drago approach has been much favoured by Fowkes [21-23,34,132-136]. Using calorimetric data, $C$ and $E$ parameters have been obtained for a variety of organic solids and inorganic solids that are relevant to polymer systems. The fact that four parameters are needed, however, somewhat hinders the wide use of the Drago concept and focuses attention on Gutmann's approach. Other reasons for the preference for the approach of Gutmann are that sufficient data are available for the volatile probes that are suitable for IGC experiments (larger than for Drago's scale), and more importantly, the fact that the Gutmann's approach considers the amphoteric nature of most polar probes, which allows for the determination of $K_{\mathrm{a}}$ and $K_{\mathrm{b}}$.

All of the above mentioned methods that allow the determination of $\Delta G_{\mathrm{a}}^{\mathrm{s}}$ (and thus, of $\Delta H_{\mathrm{a}}^{\mathrm{s}}$ and $\Delta S_{\mathrm{a}}^{\mathrm{s}}$ ) of polar probes by the use of a $n$-alkanes reference line, can be used in the determination of $K_{\mathrm{a}}$ and of $K_{\mathrm{b}}$. It has been shown [137] that nearly identical values of specific surface energy, of enthalpy of adsorption and of $K_{\mathrm{a}}$ and $K_{\mathrm{b}}$ parameters are obtained with any of the options for data presentation, namely when the saturation vapour pressure, the normal boiling temperature or $a\left(\gamma_{1}^{\mathrm{d}}\right)^{0.5}$ are used.

Other approaches exist, such as the Goss approach (based on the van Oss approach) [107]. The Goss approach and the van Oss approach, for the determination of the acid-base contribution to the surface energy are directly related to the free energy of the acid-base interactions and not to the enthalpy as is the case with Gutmann's approach. This gives several advantages as it puts the acid-base surface parameters on the same (free energy related) basis as the van der Waals parameters. Furthermore, the determination of the temperature dependence of the specific component of the free energy of adsorption is not necessary to any further extent.

A final remark regarding the interpretation of IGC results should be made. In order to favour the establishment of equilibrium conditions between the stationary phases and the mobile phases in an

Table 2

Values of DN and $\mathrm{AN}^{*}$, of the surface area and of $a\left(\gamma_{1}^{\mathrm{d}}\right)^{0.5}$ for polar probes

\begin{tabular}{lllrr}
\hline Probe & $a\left(\mathrm{~nm}^{2}\right)$ & $a\left(\gamma_{1}^{\mathrm{d}}\right)^{0.5}\left(\mathrm{~cm}^{2}\left(\mathrm{~mJ} \mathrm{~cm}^{-2}\right)^{0.5}\right)$ & $\mathrm{AN}^{*}(\mathrm{~kJ} / \mathrm{mol})$ & $\mathrm{DN}(\mathrm{kJ} / \mathrm{mol})$ \\
\hline Trichloromethane & 0.440 & $2.24 \mathrm{E}-16$ & 22.7 & 0.0 \\
Dichloromethane & 0.315 & $1.65 \mathrm{E}-16$ & 16.4 & 0.0 \\
Diethyl ether & 0.138 & $1.82 \mathrm{E}-16$ & 5.9 & 80.6 \\
Acetone & 0.425 & $1.73 \mathrm{E}-16$ & 10.5 & 71.4 \\
Tetrahydrofuran & 0.450 & $2.13 \mathrm{E}-16$ & 2.1 & 84.4 \\
Ethyl acetate & 0.397 & $1.95 \mathrm{E}-16$ & 6.3 & 71.8 \\
\hline
\end{tabular}


IGC experiment, the quantities of vapour that are injected are extremely small (e.g. nanolitre range of concentration). Surfaces are not generally energetically uniform. The small amounts of available vapour, therefore, will tend to adsorb on the most energetic fraction of available sites $[11,14,83,105]$. Surface energy and acid-base characteristics, obtained from IGC, will, therefore, describe the performance of these surface fractions and not necessarily the performance of the surface as a whole. More detailed descriptions of solid surfaces would necessitate the determination of adsorption isotherms of site energy distributions [73,116,138-142]. In many instances, however, the dominant surface interactions of a solid will be those involving the high-energy sites [11,25].

\subsubsection{Lewis acid-base interaction numbers from IGC evaluations}

The ability of the IGC technique to provide Lewis acid-base parameters for polymers and other materials used in polymeric systems, has lead to the development of Lewis acid-base pair interaction numbers. In this manner, an attempt to quantify the acid-base interactions at interfaces and/or interphases between a polymer matrix and additives present in the composition, making use of $K_{\mathrm{a}}$ and $K_{\mathrm{b}}$, can be carried out. The lack of theory to guide such a calculation results in the use of empiricism. In this context, several Lewis acid-base interaction parameters, based on $K_{\mathrm{a}}$ and $K_{\mathrm{b}}$, can be found in the literature $[14,24,94,105,143,144]$ :

$$
\begin{aligned}
& I_{\mathrm{sp}_{1}}=\left(K_{\mathrm{a}}\right)_{1}\left(K_{\mathrm{b}}\right)_{2}+\left(K_{\mathrm{a}}\right)_{2}\left(K_{\mathrm{b}}\right)_{1} \\
& I_{\mathrm{sp}_{2}}=\left[\left(K_{\mathrm{a}}\right)_{1}\left(K_{\mathrm{b}}\right)_{2}\right]^{1 / 2}+\left[\left(K_{\mathrm{a}}\right)_{2}\left(K_{\mathrm{b}}\right)_{1}\right]^{1 / 2} \\
& I_{\mathrm{sp}_{3}}=\left(K_{\mathrm{a}}\right)_{1}\left(K_{\mathrm{b}}\right)_{2}+\left(K_{\mathrm{a}}\right)_{2}\left(K_{\mathrm{b}}\right)_{1}-\left(K_{\mathrm{a}}\right)_{1}\left(K_{\mathrm{a}}\right)_{2}-\left(K_{\mathrm{b}}\right)_{1}\left(K_{\mathrm{b}}\right)_{2}
\end{aligned}
$$

Here $\left(K_{\mathrm{a}}\right)_{1}$ and $\left(K_{\mathrm{b}}\right)_{1}$ correspond to the Lewis acidity/basicity constants of species 1 and $\left(K_{\mathrm{a}}\right)_{2}$ and $\left(K_{\mathrm{b}}\right)_{2}$, to those of species 2. All of these parameters are reported [105] to correlate usefully with adhesion phenomena and with other properties that are influenced by the strength of Lewis acid-base intermolecular forces. Although the relations that are expressed in Eqs. (44)-(46) are empirical, the rationale for Eq. (46) is that in a random mixing process there is a high probability of finding both unlike and like interaction sites of the two constituents in close contact [24,94]. However, several remarks must be made regarding the use of the interaction parameters that is represented by Eqs. (44)(46).

Firstly, the parameters $I_{\mathrm{sp}_{1}}$ and $I_{\mathrm{sp}_{2}}$ do not take into account the Lewis base-base repulsion forces and the Lewis acid-acid repulsion forces. The Lewis base-base repulsions and the Lewis acid-acid repulsions and the Lewis acid-base attractions, do not contribute equally to the overall specific interactions. The attractions have a greater contribution, according to Fowkes [20] and Hegedus and Kamel [85]. Lewis acid-acid repulsions and Lewis base-base repulsions do make a significant contribution in those particular systems were Lewis acid-base attraction does not exist or is very weak, as has been postulated and experimentally proven, by Schreiber et al. $[3,35,94,145]$ and by Lee et al. [49] and suggested by Utracki et al. [2]. Moreover, according to Kloubek and Schreiber [145], Lewis acid-acid and Lewis base-base (repulsive) interactions do, in some cases, exceed the effects of Lewis acid-base attractive forces at interfaces, has is the case for interfaces between perfluorohydrocarbons and water. An example of the lack of acid-base attraction interaction due to predominant base-base repulsion is the incapacity of an acetone molecule to form $\mathrm{H}$-bonds with another acetone molecule [17]. This has lead to the proposal of a new parameter, $I_{\mathrm{sp}_{3}}[35,145,146]$. In the formulation of parameter $I_{\mathrm{sp}_{3}}$, it is assumed that acid-acid and base-base repulsion make the same contribution as is provided by acid-base attraction for the overall interaction potential. However, when determining the interaction parameter involving the interaction of a hypothetical material with itself or between 
identical molecules (Table 3, values of $K_{\mathrm{a}}$ and $K_{\mathrm{b}}$ being presented as an example), the value of $I_{\mathrm{sp}_{3}}$ is always negative or zero, and thus, interaction is not favoured. Consequently, no polar molecule would interact through acid-base intermolecular interactions (from the attractive point of view) with another molecule that is chemically identical.

Secondly, the contribution of acid-base attraction and of acid-acid and base-base repulsion, to the total interaction potential, is a function not only of the intrinsic Lewis acidity of the molecules and the Lewis basicity of the molecules, but is also a function of the accessibility of such interaction sites $[15,16,20,94,107,147]$.

This factor is of considerable importance when long chains (as is the case with polymers) are present, or when particulates are involved. In such instances, conformational factors and configurational factors influence the accessibility of the interaction sites [20,147]. Factors, such as the localisation and the distribution of the Lewis acidic sites and of the Lewis basic sites and their accessibility by the Lewis acidic sites and the Lewis basic sites of the interacting species, influenced by the existence of bulky side-groups, for instance, will affect the effectiveness of any acid-base interactions. Steric hindrance influences the interaction of the probe molecules that are used in IGC with the surface, and thus, is quantified in $K_{\mathrm{a}}$ and $K_{\mathrm{b}}$. However, when the material interacts with another surface (particulates, polymers), instead of with a probe molecule, the accessibility of the Lewis acidic sites and the Lewis basic sites in the materials involved is by far more influenced by conformational and morphological factors.

The thermodynamic properties determined by IGC are normalised per mole of adsorbate and per unit of surface area of adsorbent, and thus, are real indications of the likehood, strength and stability of filler-polymer interactions. Nevertheless, as far as inorganic particles are concerned, the thermodynamic properties do not account for differences in the specific area of the particles that can vary noticeably from inorganic species to inorganic species, thereby determining the availability of interaction sites with respect to the other components of the polymeric mixture.

As the acid-base interaction most frequently found is the H-bond (alongside with the $n-\sigma$ electron-donor-acceptor (EDA) bonding [16]), and due to its highly directional and specific character $[15,16]$, the acid-base interaction will be strongly affected by the orientation and accessibility of the functional groups. Accordingly and in conjunction with the acid-base properties of each material/ molecule, the contribution of acid-acid repulsion and base-base repulsion to the interaction potential will vary with the chemical nature as well as with the spatial structure of the species involved. The repulsive interaction is expected to be significant in such cases, where in both materials, either the Lewis basic sites or the Lewis acidic sites are dominant to a large extent [12] and are easily accessible.

Thirdly, in interactions between different materials that might be used as part of a multicomponent polymeric system, the probability of acid-base interactions is a function, not only of the interaction potential, but also of the number of interaction opportunities, as defined by the relative presence of each species in the polymeric system.

Table 3

Value of $I_{\mathrm{sp}_{3}}$, for the acid-base interaction potential of a hypothetical material with itself

\begin{tabular}{llr}
\hline$K_{\mathrm{a}}$ & $K_{\mathrm{b}}$ & $I_{\mathrm{sp}_{3}}$ \\
\hline Low (0.1) & Low (0.1) & 0.00 \\
Low (0.1) & High (1) & -0.81 \\
High (1) & Low (0.1) & -0.81 \\
High (1) & High (1) & 0.00 \\
\hline
\end{tabular}

Values of $K_{\mathrm{a}}$ and $K_{\mathrm{b}}$ are given only as an example. 
Therefore, an interaction parameter that is considered to be suitable for multicomponent polymeric systems, whose components are able to interact through specific interaction forces, would be influenced by the following factors:

(a) $K_{\mathrm{a}}$ and $K_{\mathrm{b}}$, the Lewis acidic and Lewis basic constants for each species;

(b) the accessibility of the Lewis acidic sites and the Lewis basic sites in each species, relative to the Lewis acidic sites and the Lewis basic sites of the interacting species, due to the presence of bulky side-groups, molecular conformations and morphological structural features of the species involved;

(c) the larger contribution of acid-base attraction forces for the overall interaction;

(d) the relative presence of each species in the blend.

In view of the above comments, an analysis of $K_{\mathrm{a}}$ and $K_{\mathrm{b}}$, taking into account the chemical structure of the species involved, their relative amounts in the blend and their physical properties (size and morphology), is thought to be the best way of predicting the acid-base interaction capability of the species that are present in multicomponent polymeric systems.

Although acid-base interactions are known to be determinant, their importance should not be exaggerated. Dispersion forces still exercise a great influence on the behaviour of multicomponent systems and their contribution is not to be neglected when interpreting property data and when selecting materials for polymeric compositions $[11,105]$.

\subsubsection{A case study: phase separation and phase preferences phenomena in pigmented}

$P C / P B T$ blends as evaluated by means of IGC

The case study presented is based on the research work carried out at our laboratories, concerning the phase separation and phase preferences phenomena that occur in multicomponent polymeric systems $[75,148,149]$.

The polymeric system studied was a mass-coloured thermoplastic alloy of a bisphenol A polycarbonate (PC) and a poly(butylene terephthalate) (PBT), vide Fig. 2. A core-shell type elastomer (MBS rubber) is added to the polymer blend to improve its impact toughness. The amorphous PC provides the impact resistance, the toughness and the dimensional stability at elevated temperatures. The semi-crystalline PBT provides the chemical resistance and the thermal stability. The degree of chemical resistance of these blends is directly related to the relative percentage of PBT. In general, the higher the percentage of PBT, the higher is the chemical resistance of the blend. The MBS rubber impact modifier consists of a core of poly(styrene), an inner layer of poly(butadiene) and a shell of poly(methyl methacrylate). The PMMA-shell of this impact modifier gives "good adhesion" with the polycarbonate, in which the impact modifier is to be dispersed. The poly(butadiene) is the component that causes the higher impact strength. The poly(styrene) layer has an aesthetic function. It is used in the impact modifier to ensure the proper reflection of light.

The matrix itself is created by extrusion of a mixture of the PC, of the PBT granulate, of the MBS rubber and of additives (including anti-oxidants and a transesterification stabiliser). The blend displays a co-continuous morphology, with a designed miscibility level of approximately $5-10 \%$, as deter-



(a)

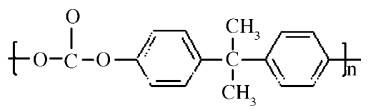

(b)

Fig. 2. Repeating unit in: (a) poly(butylene terephthalate) and (b) bisphenol A polycarbonate. 
mined by dynamic mechanical thermal analysis (DMTA) of the changes to the glass transition temperatures of PC and PBT that occur upon mixing of these polymers.

In Fig. 3 is presented a typical TEM image of the PC/PBT/MBS blends, along with a schematic interpretation of the characteristic morphology observed. The TEM image corresponds to the crosssection of a tensile bar processed using an unpigmented blend.

In the TEM image presented in Fig. 3, the PC domains can be identified with the darker areas and the PBT phase with the lighter areas. The impact modifier (MBS rubber) particles are seen in the PC phase as small dark particles.

Commercial, pigmented, PC/PBT/MBS blends (for example, Xenoy ${ }^{\circledR}$, from GE Plastics) are currently commercialised in several colours, such as yellow, red, green, purple, brown, white and black, with an overlaid polyurethane clear coating to improve the weatherability. In the mass colouration of plastics, the pigment is added to the polymer matrix either during extrusion or during moulding. Some of the advantages of the mass colouration method over more traditional methods of decorating and/or colouration, such as painting or coating the plastic parts, include technological aspects, aesthetic aspects, lower cost factors and better environmental prospects. On the other hand, mass colouration can lead to a reduction in the material properties, such as weatherability, physical properties and mechanical properties.

The effect of a pigment on such a system is dependent on the level of interaction between the various components of the blend. Thus, fundamental studies relating to the interactions between colourants and the remaining components of the polymer blends are of crucial importance to an understanding of the properties (physical, mechanical and colouristic) of these commercially important polymeric systems.

Inverse gas chromatography, carried out at infinite dilution, was used to study the surface Lewis acid-base properties of the major components of pigmented PC/PBT/MBS rubber blends (45/45/ $10 \mathrm{wt} . \%)$. Additionally, the dispersive component of the surface tension of the materials studied was determined, allowing for an assessment of the interaction capability through dispersive forces. The analysis of $K_{\mathrm{a}}$ and $K_{\mathrm{b}}$, accompanied by the analysis of the chemical structure of the implicated molecules, the relative amounts of each compound in the blend and their physical properties (size and morphology), provided the rationale for an interpretation of the phase separation (partial miscibility) and the phase preferences that exist in these systems and of the consequences of these phenomena to their physical properties and to their mechanical properties.

In Fig. 4 are compared the values of $K_{\mathrm{a}}$ and $K_{\mathrm{b}}$ relating to the surface of the pigment studied (C.I. Pigment Blue 28), of the MBS rubber, of the PC and of the PBT.

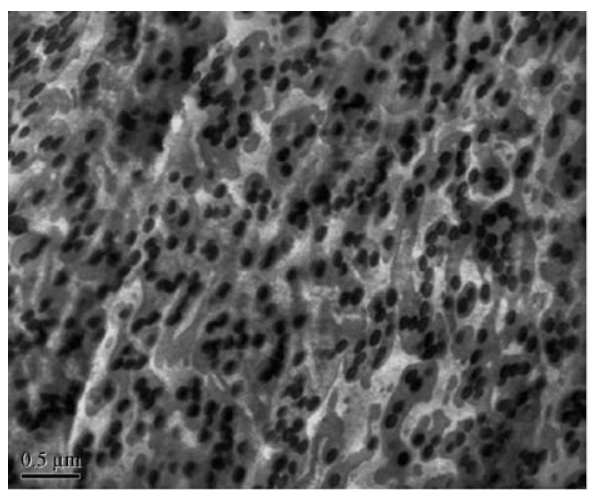

Unpigmented Blend - BX

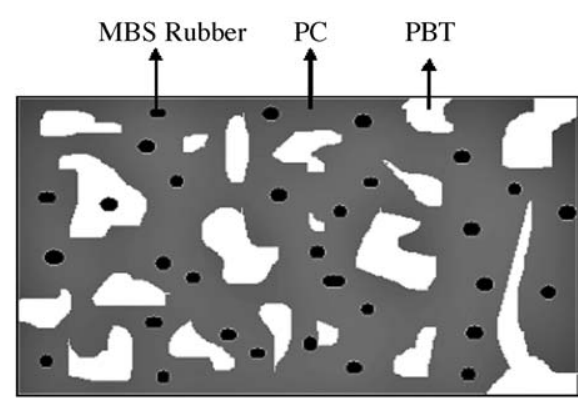

Fig. 3. TEM image of an unpigmented PC/PBT/MBS blend. 

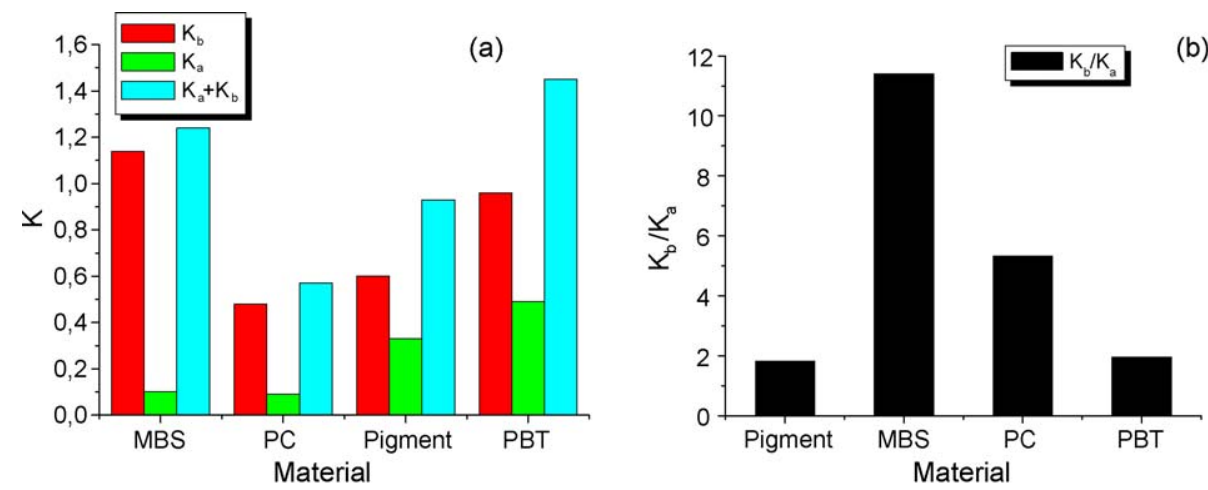

Fig. 4. Comparison of the values of the $K_{\mathrm{a}}$ and of the $K_{\mathrm{b}}$ for the surface of the materials studied.

The results presented in Fig. 4 show that the PBT and the impact modifier are the most interactive materials (greater $K_{\mathrm{a}}+K_{\mathrm{b}}$ value). The $\mathrm{PC}$ is significantly less interactive than the remaining materials. The impact modifier has the greater predominance of basic sites and the PC has the lower predominance of basic sites. The impact modifier and the PBT are the more Lewis basic materials. The PBT and the C.I. Pigment Blue 28 are the more Lewis acidic materials.

From the data presented and bearing in mind the above discussion concerning the analysis of the Lewis acid-base interaction potential, the following conclusions can be drawn. The PBT interacts preferentially intramolecularly and intermolecularly, with PBT molecules, as they are characterised by both strong Lewis base and strong Lewis acid functionalities. The PC has the lower ability to participate in specific interactions. This is due to the strong base-base repulsion and weak acid-base attraction, alongside with the steric hindrance that is due to the $-\mathrm{CH}_{3}$ side-groups and to the aromatic ring (Fig. 2). The fast crystallisation kinetics of PBT contributes to the expulsion of $\mathrm{PC}$ from within the PBT domains. This fast crystallisation kinetics is interpreted as the contribution of the strong Lewis basic sites and of the strong Lewis acidic sites, of the chemically regular structure of the molecule, of the non-existence of bulky side-groups and of the high mobility that is caused by the butylene unit in the chain (Fig. 2). These aspects provide the structural and chemical requirements for crystallinity, and consequently, for the excellent solvent resistance and thermal stability that is possessed by PBT.

A certain degree of Lewis acid-base attraction between the PC and the PBT is expected as the PC, although being a weak Lewis acid, has some Lewis base character and the PBT has strong Lewis acidic sites. Furthermore, the PBT also has strong Lewis basic sites, and thus, are able to interact to a certain extent with the Lewis acidic sites on PC. One must also bear in mind that, usually, the PBT and the PC account for $90 \%(\mathrm{w} / \mathrm{w})$ of these blend compositions, in an approximate 1:1 proportion and that, therefore, the interaction opportunities are very considerable.

It has been shown by several research laboratories that possibility of miscibility through the repulsion effect exists $[2,49,50]$. The repulsion effect in the case of PC and PBT requires that at least one of the polymers be regarded as an alternating copolymer consisting of constituents with a large difference in polarity. Bearing in mind the repeating unit in PBT (Fig. 2), one can identify the aforementioned constituents as being the ester functionality (strongly basic) and the hydroxyl groups (strongly acidic). As the number of ester groups per unit chain is significantly greater than the number of $\mathrm{OH}$ groups, it follows that base-base repulsion between the basic centres in the backbone of PBT is a probable event. Consequently, PBT and in view of the repulsion effect theory, are expected to interact with PC, although to a small extent. Thus, while being naturally phase-separated, PC and PBT may be miscible to a small extent. 
Sanchez et al. [150] and Dekkers et al. [151] reported good interfacial adhesion existing between PBT and PC in transesterification-free compositions. Moreover, Mishra and Venkidusamy [152] showed, by means of IR studies, that additions of PBT improves the intermolecular forces in PBT/PC blends, in particular, in the end-group and the $-\mathrm{CH}_{3}$ and $-\mathrm{C}=\mathrm{O}$ groups. These results further support the evidence given in the present report of the decisive role of Lewis acidic/basic centres on the partial miscibility of PBT with PC.

The preference of the impact modifier for interaction with the PC rather than with the PBT, reported by several researchers [153-158] and in the light of the results presented in Fig. 4, is interpreted in terms of the preference of the PBT to interact intramolecularly and intermolecularly with PBT molecules and of the Lewis base-base repulsion (predominant repulsion effect) between the PBT and the impact modifier. The predominant repulsion effect, in this case, is due to the fact that the PBT and the MBS rubber shell (PMMA) are very strong bases and the surface Lewis acidity of the impact modifier is low (and therefore, the impact modifier will interact mainly through the basic sites). As the PC has the weakest Lewis basicity and weakest Lewis acidity, the base-base repulsion with the MBS will not be as significant as between the impact modifier and the PBT. Thus, acid-base attraction is thought to dominate in the pair MBS rubber/PC. Also, the PBT and the PC are used in an approximately $1: 1$ proportion, meaning that the interaction opportunities between the MBS and the PC are substantial. The interaction between PC and PMMA has been shown, by Nishimoto et al. [159], to be weak but slightly favourable. Good adhesion between the PC and the MBS has also been reported by Dekkers et al. [151]. The fast crystallisation of PBT also contributes to the expulsion of the impact modifier from the PBT domains.

From the previous interpretation of the data presented in Fig. 4, C.I. Pigment Blue 28 is predicted to interact preferentially with the PBT and then with the PC. This is due to the fact that the pigment is strongly Lewis acidic and the PBT is strong Lewis basic. Also, the PBT is Lewis acidic and the pigment is moderately Lewis basic. Nevertheless, as the PBT molecules interact preferentially with other PBT molecules, it is expected that some acid-base interaction between the pigment and the PC would occur.

To support the observations/interpretations that were made on the basis of the mechanical testing results and of the physical and thermodynamic characterisation of the pigmented PC/PBT/MBS blends, the surface Lewis acid-base properties of the pigment, C.I. Pigment Blue 28, were "customised" by means of a photosensitised grafting method. The aim of this procedure was to obtain two surface-treated pigments, such that the surface of one had dominant Lewis basicity and the surface of the other had dominant Lewis acidity. On the basis of the thermodynamic characterisation, the "basic" pigment and the "acidic" pigment would be expected to have opposite phase preferences (for the PC phase and the PBT phase, respectively). These alterations to the phase preference of the pigment would result in changes to the physical and mechanical properties of the blends. In particular, if the surface acidity of the "acidic" pigment were sufficient, this pigment would be expected to significantly influence the crystallisation properties of the PBT phase and thus, the useful properties of these systems.

The surface modification method consisted of fixing MAA-based units onto the pigment surface through a photo-sensitised grafting procedure. Thus, one of the modified pigments had a significantly greater Lewis acid character than the unmodified pigment and other modified pigment had reduced surface Lewis acidity and was obtained from the "acidic" pigment by neutralisation of the surface carboxylic acid groups with $\mathrm{NaOH}$. A series of techniques was used to assess the success of the surface treatment applied to the pigment (fixation of MAA-based units). The success of the modification procedures was confirmed using TGA, EDXA, IGC, SEM and $\mathrm{pH}$ value measurements of dispersions of the pigments. 
Table 4

Specific component of the enthalpy of adsorption of the polar probes, $-\Delta H_{\mathrm{a}}^{\mathrm{s}}(\mathrm{kJ} / \mathrm{mol})$, on the surface of the pigments

\begin{tabular}{llll}
\hline Probe molecule & Unmodified pigment & Lewis acidic pigment & Lewis basic pigment \\
\hline DCM & 12.9 & 19.7 & 15.7 \\
THF & 29.2 & 71.9 & 26.6 \\
\hline
\end{tabular}

In Table 4 are compared the specific component of the enthalpy of adsorption of DCM (Lewis acidic probe) and of THF (Lewis basic probe), on the surface of the unmodified pigment and on the surface of the surface-treated pigments.

From the data presented in Table 4, it can be observed that the surface Lewis acidity of the modified Lewis acidic pigment is greatly increased upon the surface treatment of C.I. Pigment Blue 28. When the surface carboxylic groups are neutralised, to provide the Lewis basic pigment, the Lewis acidity is significantly reduced and close to that of the unmodified pigment. The surface Lewis basicity increases due to the surface treatment and is slightly reduced upon neutralisation of the surface carboxylic acid groups. The changes observed in terms of the surface Lewis acidity/basicity are in line with the presence of MAA-based polymeric species on the surface of the treated C.I. Pigment Blue 28. The total interaction potential of the surface of C.I. Pigment Blue 28 is greatly increased by the introduction of MAA-based units on its surface and is reduced after the neutralisation of the carboxylic groups in these units. The relative presence of Lewis basic sites to Lewis acidic sites is decreased due to the surface treatment. It increases upon neutralisation of the surface carboxylic acid groups of the Lewis acidic pigment, relative to that of the unmodified pigment.

Thermal analysis (DSC, DMTA), molar masses analysis (GPC) mechanical testing (izod impact, tensile) and microscopic characterisation (SEM/EDXA, TEM), were used in order to confirm the expectations relative to the phases preferences of the pigments (unmodified and modified versions). The unmodified pigment was successfully proven to be preferentially located at the PC/PBT interphase, the "Lewis acidic" pigment in the PBT-rich phase and the "Lewis basic" pigment in the PC-rich phase. Altering the preferential location and adhesion characteristics of the pigment allowed the optimisation of the useful properties of the PC/PBT/MBS blends. The improvement in the adhesion between the pigment and the PC and the PBT, along with the changes to the phase preferences of the pigment, result in: (1) lower viscosity of the pigmented blends, due to improved dispersion of the modified pigments in the polymeric matrix; (2) very significant reduction of the transesterification reactions and of the thermal scission of the polymers, namely at the lower pigment loadings; (3) more consistent viscoelastic behaviour of the blends with varying pigment loading; (4) less pronounced dependence of the impact resistance on temperature.

\section{Conclusions}

The intermolecular forces operating in multicomponent polymeric systems contribute decisively to the useful properties of these systems. Several approaches exist that allow for an interpretation, forecast and optimisation of the interactions occurring in such complex systems. These include the use of solubility parameters, of interaction parameters from polymer solution theories, of the concept of work of adhesion and interfacial tension and of diverse thermodynamic parameters and thermodynamic-based semi-empirical parameters obtained by inverse gas chromatography.

All of these approaches have valuable advantages and relevant drawbacks. Thus, it is recommended the simultaneous use of several alternative approaches in order to corroborate the experimental results, analyses and theoretical predictions. 
The use of the Lewis acid-base concept has been shown to be most useful in the interpretation and prediction of interactions occurring in complex multicomponent polymeric systems and in the interpretation of consequences of such interactions to the physical and mechanical properties of these systems.

\section{References}

[1] A.J. Ryan, Nat. Mater. 1 (2002) 8-10.

[2] L.A. Utracki, D.J. Walsh, R.A. Weiss (Eds.), Multiphase Polymers: Blends and Ionomers, A.C.S., 1989, pp. 1-35.

[3] H.P. Schreiber, F.S. Germain, J. Adhes. Sci. Technol. 4 (1990) 319-331.

[4] K. Premphet, P. Horanont, Polymer 41 (2000) 9283-9290.

[5] M.Y. Boluk, H.P. Schreiber, Polym. Composites 7 (1986) 295-301.

[6] M.Y. Boluk, H.P. Schreiber, Polym. Composites 10 (1989) 215-221.

[7] T.M. Malik, P.J. Carreau, M. Grmela, A. Dufresne, Polym. Composites 9 (1988) 412-418.

[8] E. Trujillo, C. Richard, H.P. Schreiber, Polym. Composites 9 (1988) 426-433.

[9] M. Ratzsch, G. Haudel, G. Pompe, E. Meyer, J. Macromol. Sci. A Chem. A27 (1990) 1631-1655.

[10] H. Ishida, Polym. Composites 5 (1984) 101-123.

[11] H.P. Schreiber, in: G. Akovali (Ed.), The Interfacial Interactions in Polymeric Composites, Kluwer Academic Publishers, The Netherlands, 1993, pp. 21-59.

[12] M.M. Coleman, J.F. Graf, P.C. Painter, Specific Interactions and the Miscibility of Polymer Blends, Technomic Publishing Co., Lancaster, PA, USA, 1991.

[13] Z.Y. Al Saigh, P. Chen, Macromolecules 24 (1991) 3788-3795.

[14] J. Lara, H.P. Schreiber, J. Coat. Technol. 63 (1991) 81-90.

[15] V. Ponec, Z. Knor, S. Cerny, Adsorption on Solids, Butterworths, London, 1974.

[16] P.L. Huyskens, W.A.P. Luck, T. Zeegers-Huyskens, Intermolecular Forces: An Introduction to Modern Methods and Results, Springer-Verlag, London, 1991.

[17] J.N. Israelachvili, Intermolecular and Surface Forces, Academic Press, London, 1991.

[18] A.J. Stone, The Theory of Intermolecular Forces, Claredon Press, Oxford.

[19] F.M. Fowkes, M.A. Mostafa, Ind. Eng. Prod. Res. Dev. 17 (1978) 3-7.

[20] F.M. Fowkes, in: L.H. Lee (Ed.), Adhesion and Adsorption of Polymers, Plenum Press, London, 1980, pp. 43-80.

[21] F.M. Fowkes, Rubber Chem. Technol. 57 (1983) 328-343.

[22] F.M. Fowkes, in: K.L. Mittal (Ed.), Physicochemical Aspects of Polymer Surfaces, Plenum Press, NY, 1983, pp. 583604 (Chapter 2).

[23] F.M. Fowkes, J. Adhes. Sci. Technol. 4 (1990) 669-691.

[24] H. Liang, R. Xu, B.D. Favis, H.P. Schreiber, J. Polym. Sci. B Polym. Phys. 38 (2000) 2096-2104.

[25] M. Nardin, J. Schultz, Composite Interfaces 1 (1993) 177-192.

[26] W.B. Jensen, in: K.L. Mittal, J. Anderson (Eds.), Acid-Base Interactions: Relevance to Adhesion Science and Technology, VSP, Utrecht, The Netherlands, 1991, pp. 3-23.

[27] L.H. Lee, in: K.L. Mittal, J. Anderson (Eds.), Acid-Base Interactions: Relevance to Adhesion Science and Technology, VSP, Utrecht, The Netherlands, 1991, pp. 25-46.

[28] F.M. Fowkes, in: K.L. Mittal, J. Anderson (Eds.), Acid-Base Interactions: Relevance to Adhesion Science and Technology, VSP, Utrecht, The Netherlands, 1991, pp. 93-115.

[29] D.W. Dwight, F.M. Fowkes, D.A. Cole, M.J. Kulp, P.J.L.S Sabat Jr., T.C. Huang, in: K.L. Mittal, J. Anderson (Eds.), Acid-Base Interactions: Relevance to Adhesion Science and Technology, VSP, Utrecht, The Netherlands, 1991, pp. 243-256.

[30] M.F. Finlayson, B.A. Shah, in: K.L. Mittal, J. Anderson (Eds.), Acid-Base Interactions: Relevance to Adhesion Science and Technology, VSP, Utrecht, The Netherlands, 1991, pp. 303-311.

[31] A.C. Tiburcio, J.A. Manson, in: K.L. Mittal, J. Anderson (Eds.), Acid-Base Interactions: Relevance to Adhesion Science and Technology, VSP, Utrecht, The Netherlands, 1991, pp. 313-328.

[32] D. Ma, W.E. Johns, A.K. Dunker, A.E. Bayoumi, in: K.L. Mittal, J. Anderson (Eds.), Acid-Base Interactions: Relevance to Adhesion Science and Technology, VSP, Utrecht, The Netherlands, 1991, pp. 343-361.

[33] Y.C. Huang, F.M. Fowkes, T.B. Lloyd, in: K.L. Mittal, J. Anderson (Eds.), Acid-Base Interactions: Relevance to Adhesion Science and Technology, VSP, Utrecht, The Netherlands, 1991, pp. 363-380. 
[34] F.M. Fowkes, D.W. Dwight, D.A. Cole, T.C. Huang, J. Non Cryst. Solids 120 (1990) 47-60.

[35] H.P. Schreiber, F.S. Germain, in: K.L. Mittal, J. Anderson (Eds.), Acid-Base Interactions: Relevance to Adhesion Science and Technology, VSP, Utrecht, The Netherlands, 1991, pp. 273-285.

[36] M. Alexandre, P. Dubois, Mater. Sci. Eng. R. Rep. 28 (2000) 1-63.

[37] N. Shenga, M.C. Boycea, D.M. Parksa, G.C. Rutledgeb, J.I. Abesb, R.E. Cohen, Polymer 45 (2004) $487-506$.

[38] K. Hedicke, H. Wittich, C. Mehler, F. Gruber, V. Altstadt, Composites Sci. Technol., in press.

[39] T.D. Fornes, D.R. Paul, Polymer 44 (2003) 3945-3961.

[40] P. Mukhopadhyay, H.P. Schreiber, Macromolecules 26 (1993) 6391-6396.

[41] J. Schultz, L. Lavielle, in: D.R. Lloyd, T.C. Ward, H.P. Schreiber (Eds.), Inverse Gas Chromatography, Characterization of Polymers and Other Materials, A.C.S., Washington, 1989, pp. 185-202.

[42] W. Zhang, A.I. Leonov, J. Appl. Polym. Sci. 81 (2000) 2517-2530.

[43] R. Fayt, R. Jerome, P. Teyssie (Eds.), Multiphase Polymers: Blends and Ionomers, A.C.S., 1989, pp. 38-66.

[44] C. Bonnerup, P. Gatenholm, J. Adhes. Sci. Technol. 7 (1993) 247-262.

[45] G. Pompe, Recent Res. Dev. Polym. Sci. 1 (1997) 109-147.

[46] Y.-Y. Cheng, M. Brillhart, P. Cebe, M. Capel, J. Polym. Sci. B Polym. Phys. 34 (1996) 2953-2965.

[47] J.G. Bonner, P.S. Hope, in: M.J. Folkes, P.S. Hope (Eds.), Polymer Blends and Alloys, Blackie Academic and Professional, London, 1993, pp. 46-65.

[48] J. Lyngaae-Jorgensen, in: M.J. Folkes, P.S. Hope (Eds.), Polymer Blends and Alloys, Blackie Academic and Professional, London, 1993, pp. 75-102.

[49] M.H. Lee, C.A. Fleicher, A.R. Morales, J.T. Koberstein, R. Koningsveld, Polymer 42 (2001) 9163-9172.

[50] H. Bertilsson, B. Franzen, J. Kubat, Plast. Rubber Process. Appl. 10 (1988) 145-153.

[51] J.T. Guthrie, Surf Coat. Int. 6 (1996) 268-273.

[52] I. Walker, A.A. Collyer, in: A.A. Collyer (Ed.), Rubber Toughened Engineering Plastics, Chapman and Hall, London, 1994, pp. 29-55.

[53] P.L. Jackson, M.B. Huglin, A. Cervenka, Polym. Int. 35 (1994) 119-133.

[54] A.J. Ryan, J.L. Stanford, R.H. Still, Polym. Commun. 29 (1988) 196-198.

[55] S.Y. Hobbs, M.E.J. Dekkers, V.H. Watkins, Polymer 29 (1988) 1598-1602.

[56] C.S. Su, D. Patterson, H.P. Schreiber, J. Appl. Polym. Sci. 20 (1976) 1025-1034.

[57] M. Galin, M.C. Rupprecht, Macromolecules 12 (1979) 506-511.

[58] T.C. Ward, D.P. Sheehy, J.E. McGrath, Polym. Prepr. Am. Chem. Soc. Div. Polym. Chem. 21 (1980) 70.

[59] W.N. Kim, C.M. Burns, Makromol. Chem. 190 (1989) 661-676.

[60] M.M. Chehimi, E. Cabet-DEliry, A. Azioune, M.L. Abel, Macromol. Symp. 178 (2002) 169-181.

[61] J. Riddle, F.M. Fowkes, J. Am. Chem. Soc. 112 (1990) 3259-3264.

[62] J.S. Vrentas, C.M. Vrentas, I.H. Romdhane, Macromolecules 26 (1993) 6670-6672.

[63] Z.Y. Al, Saigh, Int. J. Polym. Anal. Charact. 3 (1997) 249-291.

[64] Z.H. Shi, H.P. Schreiber, J. Appl. Polym. Sci. 46 (1992) 787-796.

[65] W.J. Orrts M.R., J.E. Guillet, Macromolecules 25 (1992) 949-953.

[66] E. Brendle, E. Papirer, J. Colloid Interface Sci. 194 (1997) 207-216.

[67] Y. Murakami, Polym. J. 26 (1994) 607-612.

[68] M.J. El Hibri, et al. in: D.R. Lloyd, T.C. Ward, H.P. Schreiber (Eds.), Inverse Gas Chromatography, Characterization of Polymers and Other Materials, A.C.S., Washington, 1989, pp. 120-133.

[69] T.C. Ward, D.P. Sheehy, J.S. Riffle, J.E. McGrath, Macromolecules 14 (1981) 1791-1797.

[70] Z.H. Shi, H.P. Schreiber, Macromolecules 24 (1991) 3522-3527.

[71] M.G. Prolongo, R.M. Masegosa, A. Horta, Macromolecules 22 (1989) 4346-4351.

[72] C.T. Chen, Z.Y. Al Saigh, Macromolecules 22 (1989) 2974-2981.

[73] J.E.G. Lipson, J.E. Guillet, Dev. Polym. Charact. 3 (1982) 33-71.

[74] J.E. Guillet, et al. in: D.R. Lloyd, T.C. Ward, H.P. Schreiber (Eds.), Inverse Gas Chromatography, Characterization of Polymers and Other Materials, A.C.S., Washington, 1989, pp. $20-32$.

[75] J.M.R.C.A. Santos, K. Fagelman, J.T. Guthrie, J. Chromatogr. A 969 (2002) 119-132.

[76] R. Xu, G. Tovar, H.P. Schreiber, J. Adhes. 71 (1999) 153-165.

[77] B.M. Mandak, C. Bhattcharya, S.N. Bhattacharya, Macromol. Sci. Chem. A26 (1989) 175-212.

[78] S. Klotz, et al. in: D.R. Lloyd, T.C. Ward, H.P. Schreiber (Eds.), Inverse Gas Chromatography, Characterization of Polymers and Other Materials, A.C.S., Washington, 1989, pp. 135-154.

[79] R.A.L. Jones, E.J. Kramer, Polymer 34 (1993) 115-118.

[80] E. Brendle, E. Papirer, J. Colloid Interface Sci. 194 (1997) 217-224. 
[81] R.Y. Qin, H.P. Schreiber, Langmuir 10 (1994) 4153-4156.

[82] J.M.R.C.A. Santos, K. Fagelman, J.T. Guthrie, J. Chromatogr. A 969 (2002) 11-118.

[83] J.M.R.C.A. Santos, M.H. Gil, A. Portugal, J.T. Guthrie, Cellulose 8 (2001) 217-224.

[84] C.R. Hegedus, I.L. Kamel, J. Coat. Technol. 65 (1993) 23-30.

[85] C.R. Hegedus, I.L. Kamel, J. Coat. Technol. 65 (1993) 31-43.

[86] G. Sadowski, L.V. Mokrushina, W. Arlt, Fluid Phase Equilib. 139 (1997) 391-403.

[87] W. Wang, H.P. Schreiber, Y. Yu, A. Eisenberg, J. Polym. Sci. B Polym. Phys. 35 (1997) 1793-1805.

[88] E. Papirer, J.-M. Perrin, B. Siffert, G. Philopponneau, J. Colloid Interface Sci. 144 (1991) 263-270.

[89] C.S. Flour, E. Papirer, J. Colloid Interface Sci. 91 (1983) 69-75.

[90] R. Xu, H.P. Schreiber, J. Appl. Polym. Sci. 70 (1998) 1597-1604.

[91] J. Lara, H.P. Schreiber, J. Coat. Technol. 63 (1991) 81-90.

[92] H.P. Schreiber, M.R. Wertheimer, M. Lambla, J. Appl. Polym. Sci. 27 (1982) 2269-2280.

[93] Y.J. Lee, I. Manas-Zloczower, D.L. Feke, Powder Technol. 73 (1992) 139-146.

[94] A. Ziani, R. Xu, H.P. Schreiber, T. Kobayashi, J. Coat. Technol. 71 (1999) 53-60.

[95] C.R. Herrero, E. Morales, J.L. Acosta, J. Appl. Polym. Sci. 51 (1994) 1189-1197.

[96] Z.Y. Al Saigh, Polym. News 19 (1994) 269-279.

[97] B. Li, Rubber Chem. Technol. 69 (1996) 347-376.

[98] K. Ito, J.E. Guillet, Macromolecules 12 (1979) 1163-1167.

[99] G.J. Price, in: D.R. Lloyd, T.C. Ward, H.P. Schreiber (Eds.), Inverse Gas Chromatography, Characterization of Polymers and Other Materials, A.C.S., Washington, 1989, pp. 48-57.

[100] A.M. Farooque, D.D. Deshpande, Polymer 33 (1992) 5005-5018.

[101] Q. Du, W. Chen, P. Munk, Macromolecules 32 (1999) 1514-1518.

[102] Q. Du, W. Chen, P. Munk, Macromolecules 32 (1999) 1514-1518.

[103] A. Beaumont, Ph.D. Thesis, University of Leeds, 1996.

[104] E. Papirer, H. Balard, A. Vidal, Eur. Polym. J. 24 (1988) 783-790.

[105] P. Mukhopadhyay, H.P. Schreiber, Colloids Surf. A Physicochem. Eng. Aspects 100 (1995) 47-71.

[106] H. Balard, E. Papirer, Prog. Org. Coat. 22 (1993) 1-17.

[107] K.U. Goss, J. Colloid Interface Sci. 190 (1997) 241-249.

[108] T. Hamieh, M. Rageul-Lescouet, M. Nardin, M. Rezzaki, J. Schultz, J. Chim. Phys. 94 (1997) 503-521.

[109] L. Lavielle, J. Schultz, K. Nakajima, J. Appl. Polym. Sci. 42 (1991) 2825-2831.

[110] L. Lavielle, J. Schultz, Langmuir 7 (1991) 978-981.

[111] T. Hamieh, M. Rezzaki, J. Schultz, J. Thermal Anal. 51 (1998) 793-804.

[112] M. Nardin, E.M. Asloun, J. Schultz, in: H. Ishida (Ed.), Controlled Interfaces in Composite Materials, Elsevier Science Publishing Co. Inc., 1990, pp. 285-293.

[113] M. Nardin, J. Schultz, in: G. Akovali (Ed.), The Interfacial Interactions in Polymeric Composites, Kluwer Academic Publishers, The Netherlands, 1993, pp. 81-93.

[114] M. Nardin, J. Schultz, in: G. Akovali (Ed.), The Interfacial Interactions in Polymeric Composites, Kluwer Academic Publishers, The Netherlands, 1993, pp. 95-105.

[115] G.M. Dorris, D.G. Gray, J. Colloid Interface Sci. 77 (1980) 353-362.

[116] C.S. Flour, E. Papirer, Ind. Eng. Chem. Prod. Res. Dev. 21 (1982) 666-669.

[117] D.P. Kamdem, S.K. Bose, P. Luner, Langmuir 9 (1993) 3039-3044.

[118] G. Garnier, W.G. Glasser, J. Adhes. 46 (1994) 165-180.

[119] G. Courval, D.G. Gray, Macromolecules 8 (1975) 326-331.

[120] D.G. Gray, Prog. Polym. Sci. 5 (1977) 1-60.

[121] M.M. Chehimi, E. Pigois-Landureau, J. Mater. Chem. 4 (1994) 741-745.

[122] A. Voelkel, E. Andrzejewska, R. Maga, M. Andrzejewski, Polymer 37 (1996) 455-462.

[123] A. Voelkel, E. Andrzejewska, R. Maga, M. Andrzejewski, Polymer 37 (1996) 4333-4344.

[124] E. Andrzejewska, A. Voelkel, M. Andrzejewski, R. Maga, Polymer 39 (1998) 3499-3506.

[125] J.B. Donnet, R.Y. Qin, M.J. Wang, J. Colloid Interface Sci. 153 (1992) 572-577.

[126] E. Papirer, H. Balard, E. Brendle, J. Lignieres, J. Adhes. Sci. Technol. 10 (1996) 1401-1411.

[127] V. Gutmann, Donor-Acceptor Approach to Molecular Interactions, Plenum Press, NY, 1978.

[128] H. Chtourou, B. Riedl, B.V. Kokta, J. Adhes. Sci. Technol. 9 (1995) 551-574.

[129] M.N. Belgacem, Cellulose 2 (1995) 145-157.

[130] P. Mukhopadhyay, H.P. Schreiber, J. Polym. Sci. B Polym. Phys. 32 (1994) 1653-1656.

[131] R.S. Drago, G.C. Vogel, T.E. Needham, J. Am. Chem. Soc. 93 (1971) 6014-6026. 
[132] F.M. Fowkes, Org. Coat. Plast. Chem. 40 (1979) 13-18.

[133] F.M. Fowkes, D.C. McCarthy, M.A. Mostafa, J. Colloid Interface Sci. 78 (1980) 200-206.

[134] F.M. Fowkes, Polym. Mater. Sci. Eng. 51 (1984) 522-527.

[135] F.M. Fowkes, D.C. McCarthy, D.O. Tischler, in: H. Ishida, G. Kumar (Eds.), Molecular Characterisation of Composite Interfaces, Plenum Press, London, 1985, pp. 401-411.

[136] F.M. Fowkes, J.A. Manson, T.B. Lloyd, D.O. Tischler, B.A. Shah, in: D.M. Mattox (Ed.), Mater. Res. Soc. Symp. 119 (1988) 223-234.

[137] U. Panzer, H.P. Schreiber, Macromolecules 25 (1992) 3633-3637.

[138] G.M. Dorris, D.G. Gray, J. Colloid Interface Sci. 71 (1979) 93-106.

[139] J. Anhang, D.G. Gray, J. Appl. Polym. Sci. 27 (1982) 71-78.

[140] H. Grajek, Z. Witkiewicz, Pol. J. Chem. 67 (1993) 911-921.

[141] N.L. Filippova, J. Colloid Interface Sci. 197 (1998) 170-176.

[142] A. Bagreev, F. Adib, T.J. Bandosz, J. Colloid Interface Sci. 219 (1999) 327-332.

[143] W. Wang, H. Liang, B.D. Favis, H.P. Schreiber, J. Appl. Polym. Sci. 81 (2001) 1891-1901.

[144] J. Lara, H.P. Schreiber, J. Polym. Sci. B Polym. Phys. 34 (1996) 1733-1740.

[145] J. Kloubek, H.P. Schreiber, J. Adhes. 42 (1993) 87-90.

[146] H. Liang, R. Xu, B.D. Favis, H.P. Schreiber, Polymer 40 (1999) 4419-4423.

[147] J.K. Kim, Y.W. Mai, Engineered Interfaces in Fiber Reinforced Composites, Elsevier, Amsterdam, Oxford, 1998.

[148] J.M.R.C.A. Santos, J.T. Guthrie, J. Chromatogr. A 1070 (2005) 147-154.

[149] J.M.R.C.A. Santos, Ph.D. Thesis, The University of Leeds, 2003.

[150] P. Sanchez, P.M. Remiro, J. Nazabal, J. Appl. Polym. Sci. 50 (1993) 995-1005.

[151] M.E.J. Dekkers, S.Y. Hobbs, V.H. Watkins, J. Mater. Sci. 23 (1988) 1225-1230.

[152] S.P. Mishra, P. Venkidusamy, J. Appl. Polym. Sci. 58 (1995) 2229-2234.

[153] N.A. Memon, J. Appl. Polym. Sci. 54 (1994) 1059-1072.

[154] S.Y. Hobbs, M.E.J. Dekkers, V.H. Watkins, Polym. Bull. 17 (1987) 341-345.

[155] D. Delimoy, C. Baily, J. Devaux, R. Legras, Polym. Eng. Sci. 28 (1988) 104-112.

[156] H. Bertilsson, B. Franzen, J. Kubat, Plast. Rubber Process. Appl. 11 (1989) 167-173.

[157] M.E.J. Dekkers, S.Y. Hobbs, I. Bruker, V.H. Watkins, Polym. Eng. Sci. 30 (1990) 1628-1632.

[158] S.Y. Hobbs, M.E.J. Dekkers, V.H. Watkins, J. Mater. Sci. 23 (1988) 1219-1224.

[159] M. Nishimoto, H. Keskkula, D.R. Paul, Polymer 32 (1991) 272-278. 